UNITED STATES DEPARTMENT OF THE INTERIOR

GEOLOGICAL SURVEY

GEOPHYSICAL AND LITHOLOGIC LOGS FOR THIRTEEN HOLES DRILLED IN THE BOOK CLIFFS COAL FIELD, RANGE CREEK AND WOODSIDE QUADRANGLES, EMERY COUNTY, UTAH

By

Howard F. Albee
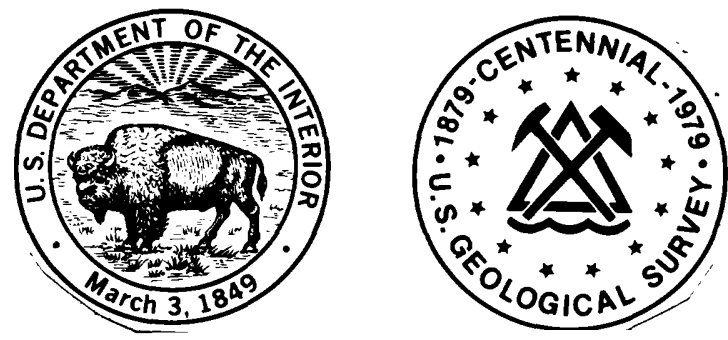

Open-File Report 79-727

1979

This report has not been edited for conformity with U.S. Geological Survey editorial standards or stratigraphic nomenclature. 


\section{ILLUSTRAT IONS}

Figure 1. Drill-hole locations in the Book Cliffs coal field, Woodside quadrangle-_-_-_-_-

2. Drill-hole locations in the Book Cliffs coal field, Range Creek quadrangle--_-_-_-_-_-_-_-_-_-_-_-_--

3. Description of rocks in the Woodside and Range Creek quadrangles-_-_-_-_-

TABLE

Table 1. Summary of information for thirteen holes drilled in the Book Cliffs coal field-- 


\title{
GEOPHYSICAL AND LITHOLOGIC LOGS FOR THIRTEEN HOLES DRILLED IN THE BOOK CLIFFS COAL FIELD, RANGE CREEK AND WOODSIDE QUADRANGLES, EMERY COUNTY, UTAH
}

\author{
By Howard F. Albee
}

\section{INTRODUCTION}

Thirteen holes, for a total of 15,475.5 feet, were rotary drilled, and five of them were partially cored, in the Book Cliffs coal field, Utah, for the U.S. Geological Survey in October 1978. An additional hole, BC-5-RC, was begun in T. 17 S., R. 15 E., sec. 22, but was abandoned at 750 feet. The drilling was done by Himes Drilling Company of Grand Junction, Colorado, under contract no. 14-08-0001-17342, awarded by the USGS. The geophysical logging was done by Strata Surveys, Steamboat Springs, Colorado. Permission to drill was granted by officials of the U.S. Bureau of Land Management, Price, Utah.

The purpose of the drilling was to obtain information on the thickness, quality, and extent of coal, and the lithology of the enclosing rocks, in the Upper Cretaceous Blackhawk Formation. The overall goal of the project is to evaluate and classify Federal lands in the public domain.

Drilling was done in the Range Creek and Woodside quadrangles, Emery County, Utah, using truck-mounted rotary drilling and coring rigs. Drilling media were air and foam for the rotary drilling and mud for the coring. Coring was done only in the upper coal-bearing member of the Blackhawk Formation.

All drill holes were logged by geophysical methods which included resistivity, natural gamma, density, and caliper. The logs were run at a scale of 1 inch to 10 feet; but for this report they were reduced to 1 inch to 50 feet.

All measurements are in feet; to convert to meters, multiply by 0.3048 . 


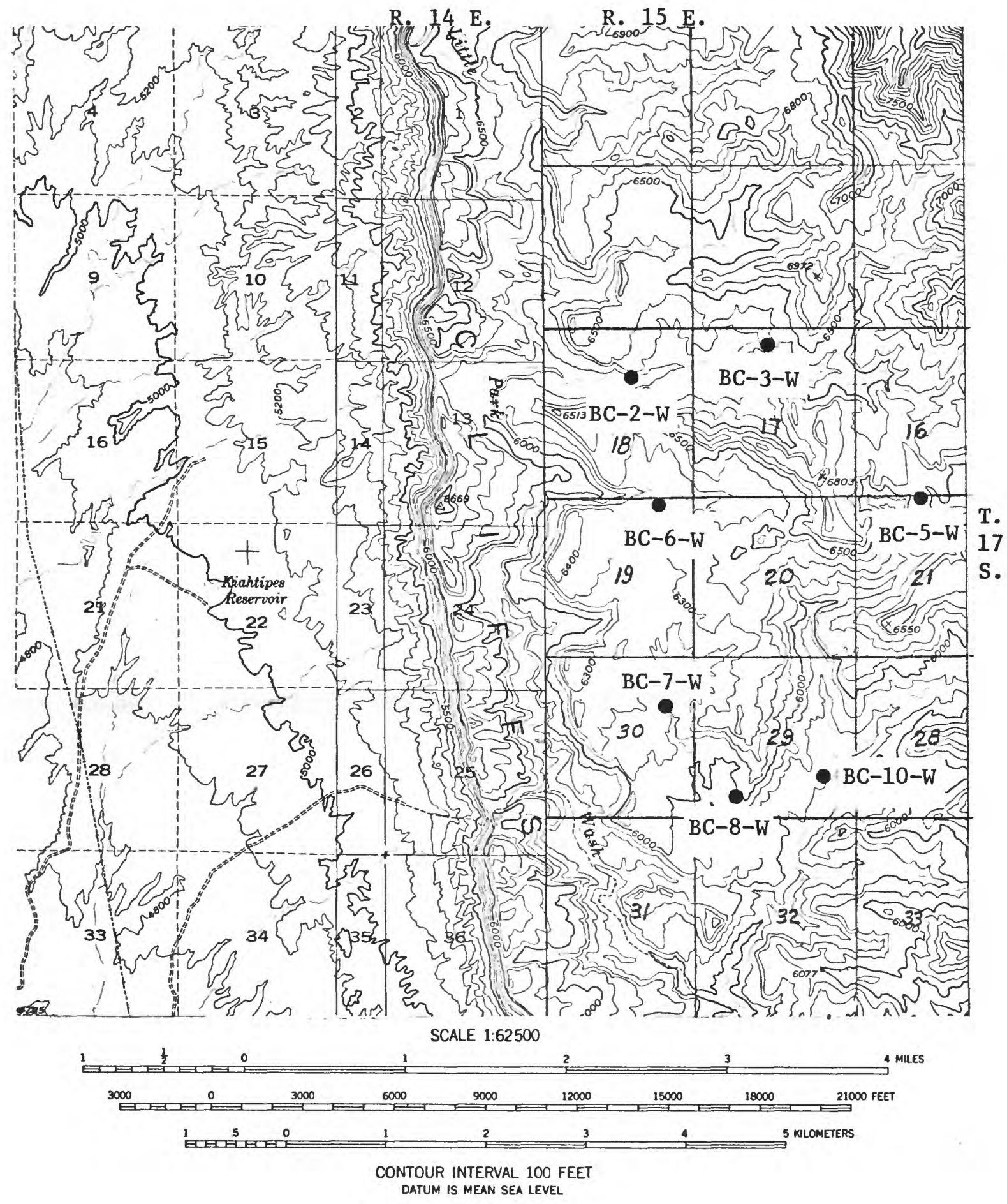

Figure 1.--Drill-hole locations in the Book Cliffs coal field, Woodside quadrangle, Emery County, Utah. 


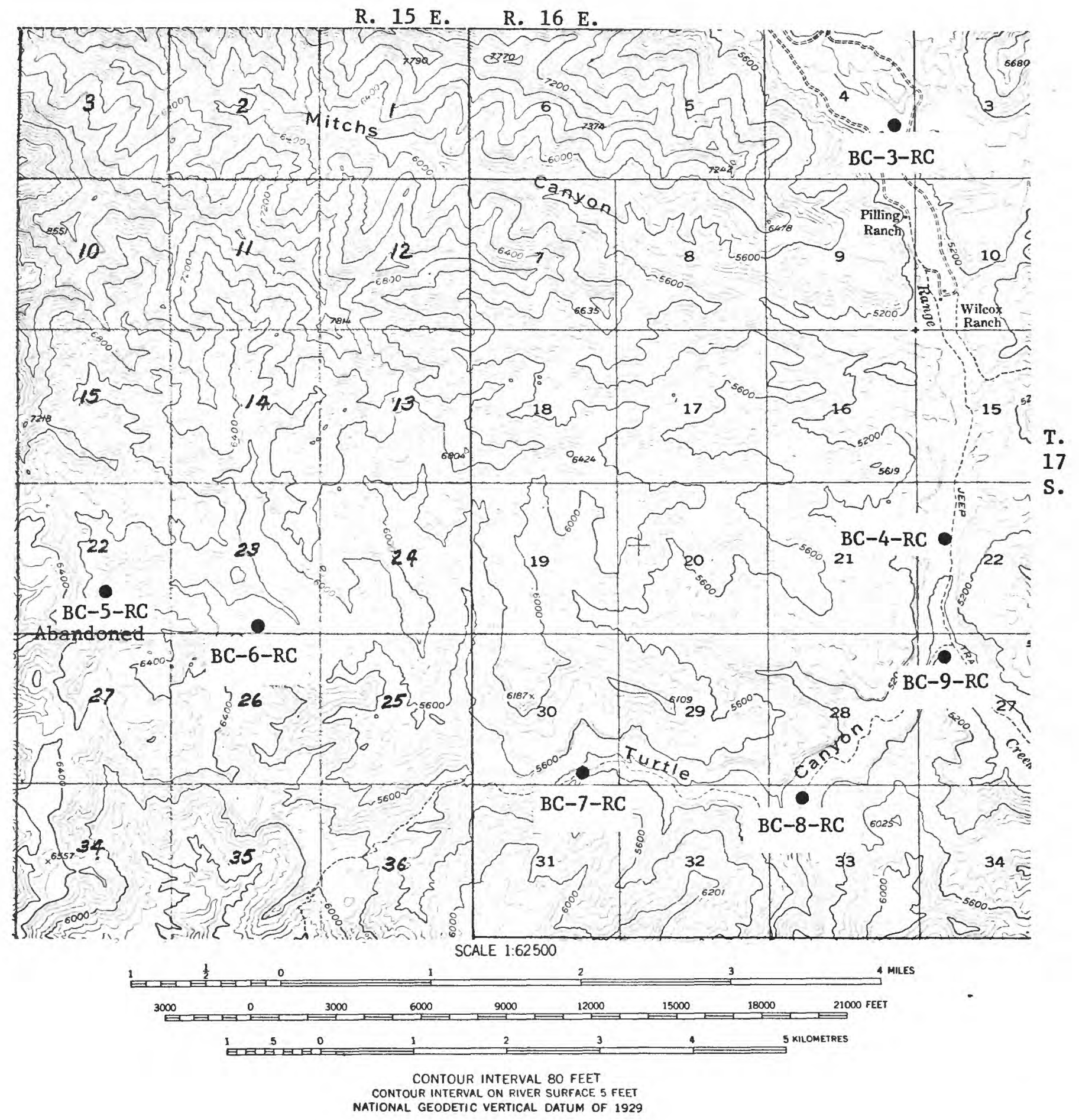

Figure 2.--Dril1-hole locations in the Book Cliffs coal fleld, Range Creek quadrangle, Emery County, Utah. 


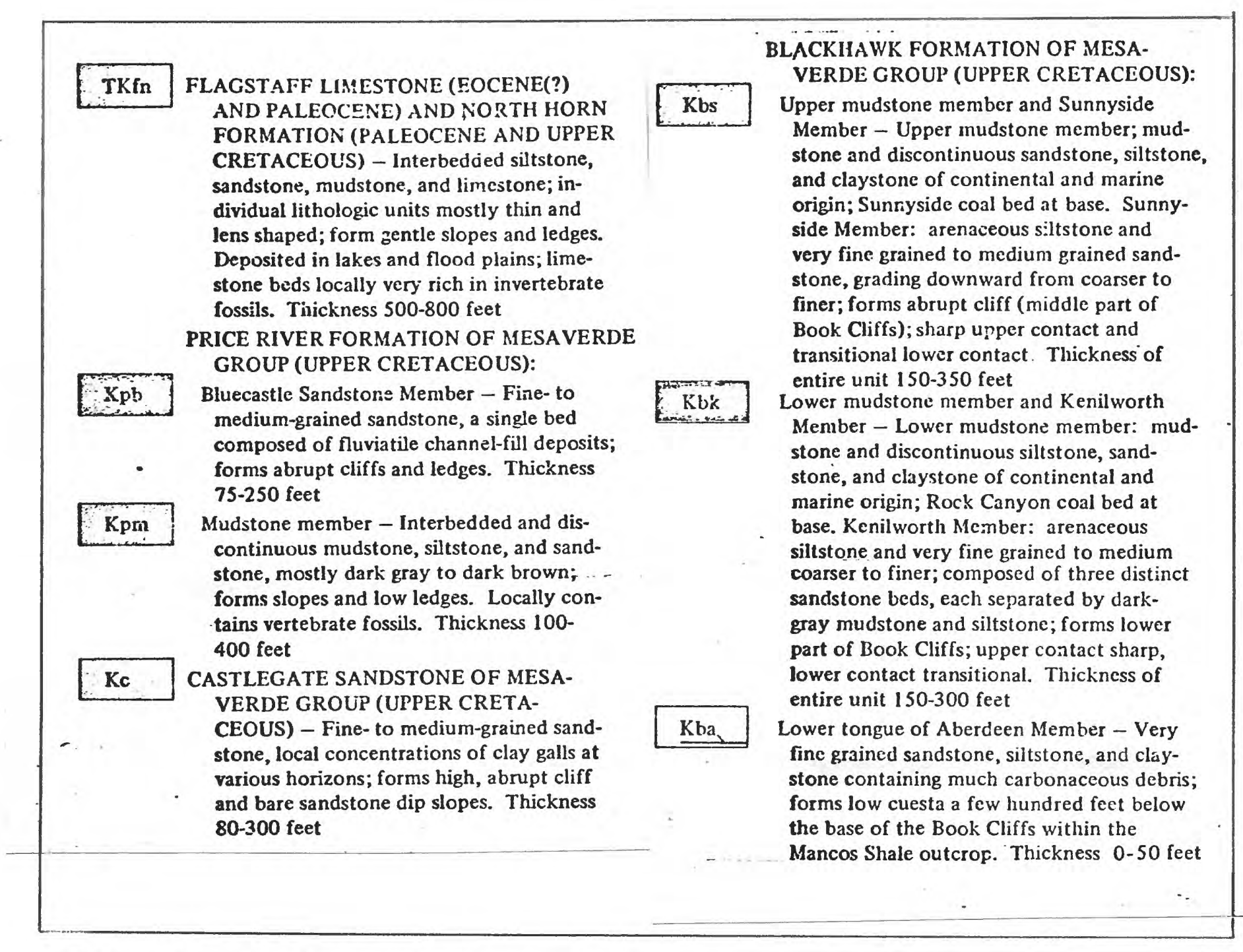

Figure 3.--Description of rocks in the Woodside and Range Creek quadrangles, Emery County, Utah. (Modified from Osterwald and Maberry, 1974.)

\section{REFERENCES}

Fisher, D. J., Erdmann, C. E., and Reeside. J. B., Jr., 1960, Cretaceous and Tertiary formations of the Book Cliffs, Carbon, Emery, and Grand Counties, Utah, and Garfield and Mesa Counties, Colorado: U.S. Geological Survey Professiona1 Paper 332, 80 p.

Osterwald, F. W., and Maberry, J. E., 1974, Engineering geologic map of the Woodside quadrangle, Emery and Carbon Counties, Utah: U.S. Geological Survey Miscellaneous Investigations Map I-798, scale 1:48,000. 
Table 1.--Summary of information for thirteen holes drilled in the Book Cliffs coal field, Range Creek and Woodside quadrangles, Emery County, Utah

[FEL, from east line; FWL, from west line; FNL, from north line; FSL, from south

1ine. A11 measurements in feet; to convert to meters, multiply by 0.3048]

\begin{tabular}{|c|c|c|c|c|c|}
\hline $\begin{array}{l}\text { Drill- } \\
\text { hole } \\
\text { No. }\end{array}$ & Location & $\begin{array}{l}\text { Rotary } \\
\text { drilled } \\
\text { depth }\end{array}$ & $\begin{array}{l}\text { Cored } \\
\text { interval }\end{array}$ & $\begin{array}{l}\text { Depth } \\
\text { logged }\end{array}$ & $\begin{array}{l}\text { Total } \\
\text { depth }\end{array}$ \\
\hline $\mathrm{BC}-3-\mathrm{RC}$ & $\begin{array}{l}\text { T. } 17 \text { S., R. } 16 \text { E., sec. } 4 \\
700 \text { FEL, 1,900 FSL }\end{array}$ & 1,700 & -- & 1,691 & 1,700 \\
\hline $\mathrm{BC}-4-\mathrm{RC}$ & $\begin{array}{l}\text { T. } 17 \text { S., R. } 16 \text { E., sec. } 22 \\
1,000 \text { FWL, 2,050 FNL }\end{array}$ & $1,122.3$ & $\begin{array}{l}1,122 \cdot 3- \\
1,272.6\end{array}$ & 1,270 & $1,272.6$ \\
\hline $\mathrm{BC}-6-\mathrm{RC}$ & $\begin{array}{l}\text { T. } 17 \text { S., R. } 15 \text { E., sec. } 23 \\
300 \text { FSL, 2,000 FEL }\end{array}$ & 1,595 & -- & 1,595 & 1,595 \\
\hline $\mathrm{BC}-7-\mathrm{RC}$ & $\begin{array}{l}\text { T. } 17 \text { S., R. } 16 \mathrm{E} . \text {, sec. } 30 \\
300 \mathrm{FSL}, 1,200 \mathrm{FEL}\end{array}$ & 931 & $\begin{array}{r}931- \\
1,083\end{array}$ & 1,081 & 1,083 \\
\hline $\mathrm{BC}-8-\mathrm{RC}$ & $\begin{array}{l}\text { T. } 17 \text { S., R. } 16 \text { E., sec. } 33 \\
700 \text { FWL, } 200 \text { FNL }\end{array}$ & 1,020 & -- & 1,019 & 1,020 \\
\hline$B C-9-R C$ & $\begin{array}{l}\text { T. } 17 \text { S., R. } 16 \text { E., sec. } 27 \\
950 \text { FWL, 1,950 FNL }\end{array}$ & 1,224 & -- & 1,222 & 1,224 \\
\hline$B C-2-W$ & $\begin{array}{l}\text { T. } 17 \text { S., R. } 15 \text { E., sec. } 18 \\
1,500 \text { FNL, 2,100 FEL }\end{array}$ & 740 & -- & 738 & 740 \\
\hline$B C-3-W$ & $\begin{array}{l}\text { T. } 17 \text { S., R. } 15 \text { E., sec. } 15 \\
350 \text { FNL, 2,100 FWL }\end{array}$ & 955.7 & $\begin{array}{l}955.7- \\
1,212\end{array}$ & 1,212 & 1,212 \\
\hline$B C-5-W$ & $\begin{array}{l}\text { T. } 17 \text { S., R. } 15 \text { E., sec. } 21 \\
100 \text { FNL, } 2,200 \text { FWL }\end{array}$ & 1,750 & --- & 1,722 & 1,750 \\
\hline$B C-6-W$ & $\begin{array}{l}\text { T. } 17 \text { S., R. } 15 \text { E., sec. } 19 \\
450 \text { FNL, } 700 \text { FEL }\end{array}$ & 759.4 & $\begin{array}{l}759.4- \\
961.8\end{array}$ & 961 & 961.8 \\
\hline BC-7-W & $\begin{array}{l}\text { T. } 17 \text { S., R. } 15 \text { E., sec. } 30 \\
900 \text { FEL, } 1,450 \text { FNL }\end{array}$ & 985 & -- & 984 & 985 \\
\hline BC- $-8-W$ & $\begin{array}{l}\text { T. } 17 \text { S., R. } 15 \text { E., sec. } 29 \\
700 \text { FSL, } 1,200 \text { FWL }\end{array}$ & 771.3 & $\begin{array}{l}771.3- \\
942\end{array}$ & 942 & 942.1 \\
\hline BC-10-W & $\begin{array}{l}\text { T. } 17 \text { S., R. } 15 \text { E., sec. } 29 \\
700 \text { FSL, } 1,150 \text { FEL }\end{array}$ & 990 & --- & 984 & 990 \\
\hline
\end{tabular}


Hole No. BC-3-RC Quadrangle Range Creek Elevation $5,250 \mathrm{ft}$

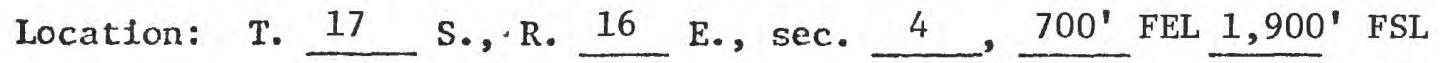

Rotarydrilled depth $1,700^{\prime}$
Cored interval Logged depth 1,691' Tota1 depth 1,700_

Geophysical logs:

Caliper (Cal) - Logging speed:

Resistivity (Res):

Gamma (Gam) :

Density (Den) : $\mathrm{ft} / \mathrm{min}$

Others: $20 . \mathrm{ft} / \mathrm{min}$

Scale:
Scale:

Scale:

15 cps/log div.

T.C. 1 sec.

$62.5 \mathrm{cps} / \log$ div.

\section{LITHOLOGY}

\section{0- 60 Alluvium}

Start drilling in Flagstaff Limestone and North Horn Formation, undifferentiated

60- 65 Limestone, gray, silty, impure

65- 80 Limestone, gray, hard, fairly pure

80- 110 Mudstone, gray, soft

110- 130 Mudstone, gray, grading to fine siltstone

130- 160 Mudstone, maroon to reddish-brown, very soft; shale, white

160- 170 Mudstone and shale, variegated

170- 280 Mudstone, gray, slightly calcareous

280- 295 Sandstone, fine- to mediumgrained, angular, relatively unclean

295- 300 Mudstone, gray, semi-hard

300- 320 Mudstone to siltstone, gray and reddish-brown, calcareous

320- 340 Mudstone, dark-gray; possibly a limestone bed between $320 \mathrm{ft}$ and $325 \mathrm{ft}$

340- 355 Sandstone, brown, medium-grained, angular, unclean

355- 370 Mudstone, gray

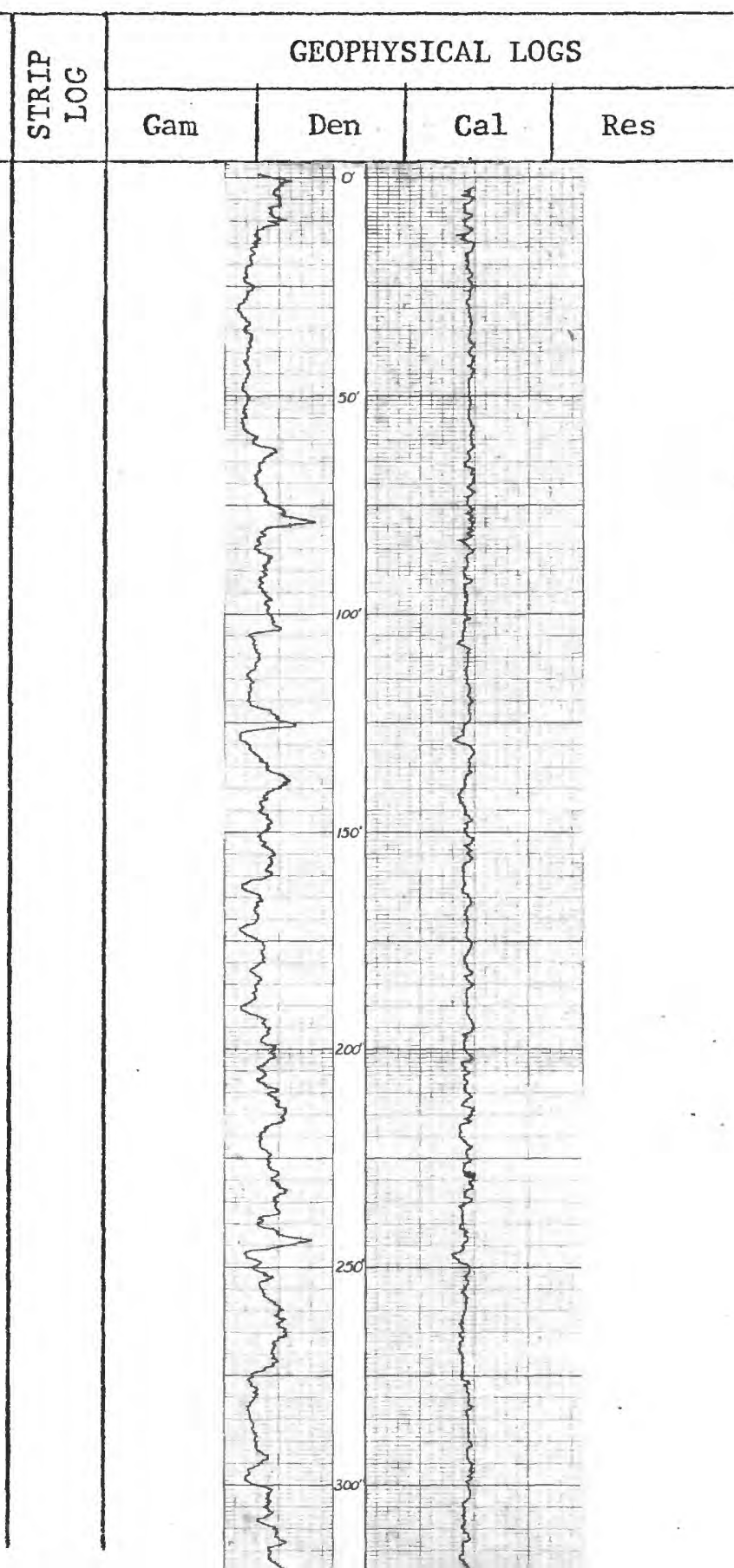




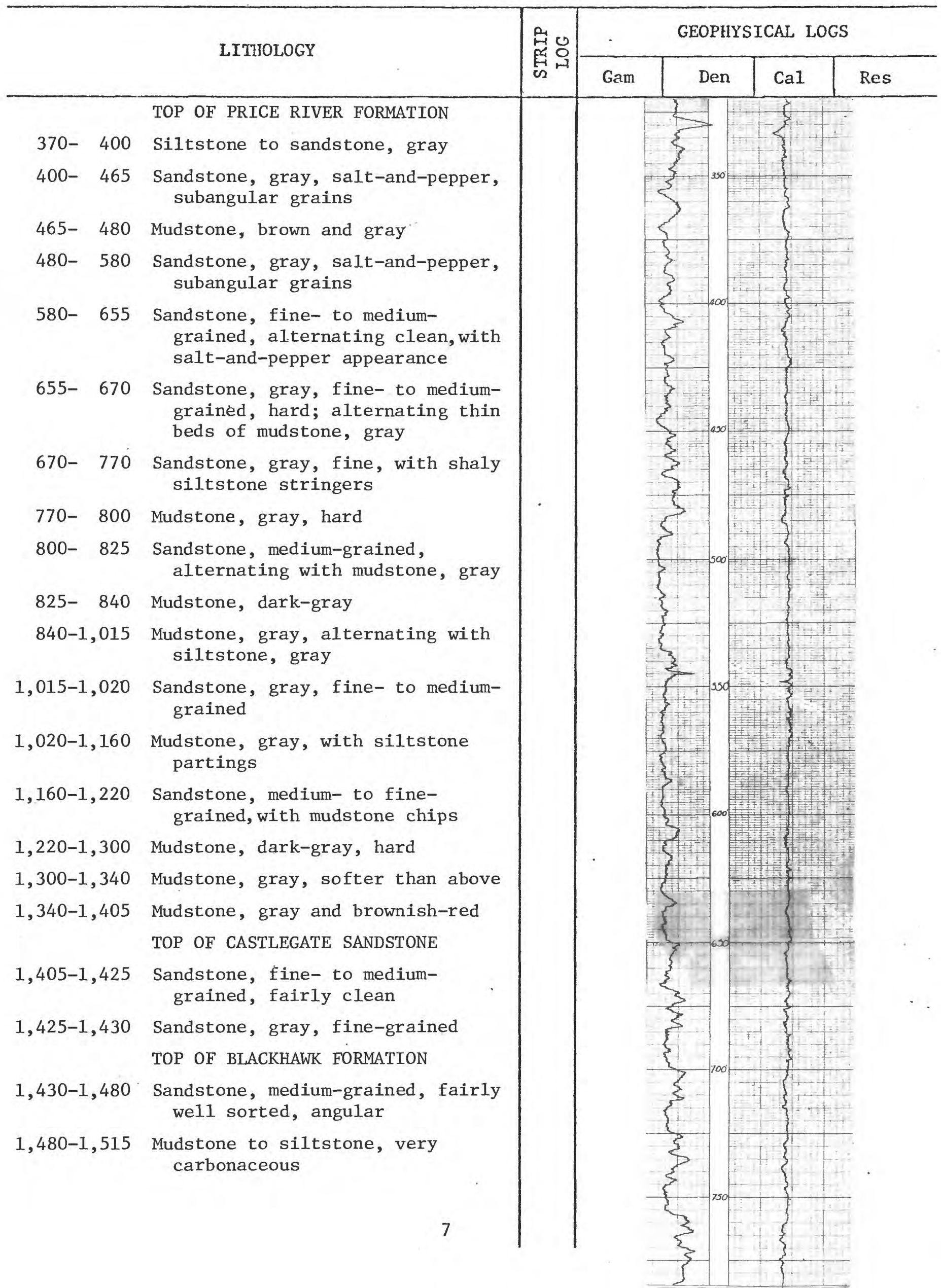




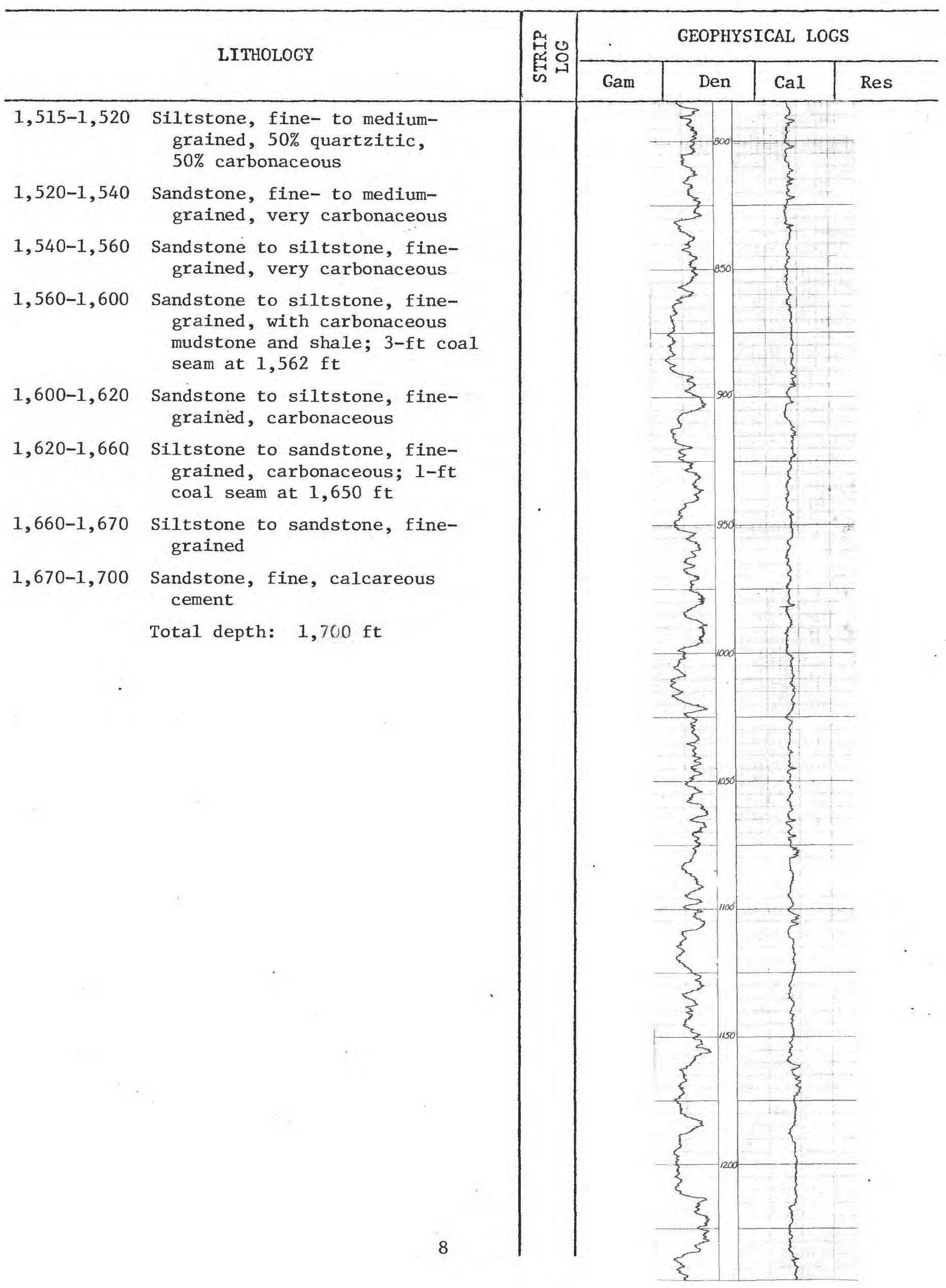


Hole No.

BC-3-RC

(continued)

LITHOLOGY

\begin{tabular}{|c|c|c|c|c|}
\hline \multirow{2}{*}{ 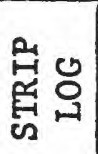 } & \multicolumn{4}{|c|}{ GEOPHYSICAL LOGS } \\
\hline & Gam & Den & $\mathrm{Cal}$ & Res \\
\hline
\end{tabular}

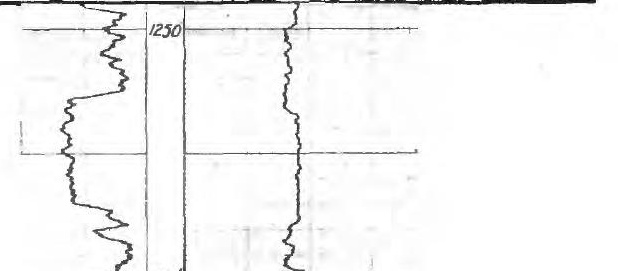


Hole No. BC-4-RC Quadrangle Range Creek Elevation $\underline{4,875 \mathrm{ft}}$

Location: T. 17 S., R. 16 E., sec. $\frac{22}{122.3}, 1,000^{\prime}$ FWL 2,050' FNL

Rotarydrilled depth $1,122.3^{\prime}$ Logged depth1,270' Total depth 1,272 Drilling medium Water, foam, and mud

Geophysical logs:

Caliper (CaI) - Logging speed: 40 $\mathrm{ft} / \mathrm{min}$.

Resistivity (Res):

Gamma (Gam):

Density (Den):
T.C. $\sec$.

T.C. 1 sec.
Others: $20 . \mathrm{ft} / \mathrm{min}$

Scale: $25 \Omega / \log$ div.

Scale:

Scale: $200 \mathrm{cps} / 1 \mathrm{log}$ div.

Remarks: Gamma not logged

\section{LITHOLOGY}

0- 80 Alluvium

80- 100 Siltstone, gray (Kpm on fig. 3)

100- 120 Sandstone, 1ight-gray, finegrained, well-indurated

120- 150 Siltstone, hard

150- 170 Sandstone, light-gray to white, fine- to medium-grained, subangular, hard

170- 185 Siltstone, gray

185- 205 Mudstone, dark-gray

205- 220 Siltstone, gray

220- 225 Sandstone, 1ight-gray, finegrained, wel1-indurated

225- 235 Mudstone, dark-gray

235- 245 Sandstone, gray, fine-grained, hard

245- 260 Siltstone to mudstone, gray

260- 270 Sandstone, gray, fine-grained, hard

270- 280 Mudstone to siltstone, gray to dark-gray, very hard

280- 300 Siltstone, gray, hard

300- 325 Sandstone, 1ight-gray, finegrained, hard

325- 340 Mudstone, dark-gray

340- 345 Siltstone, dark-gray

345- 355 Sandstone, light-gray, finegrained

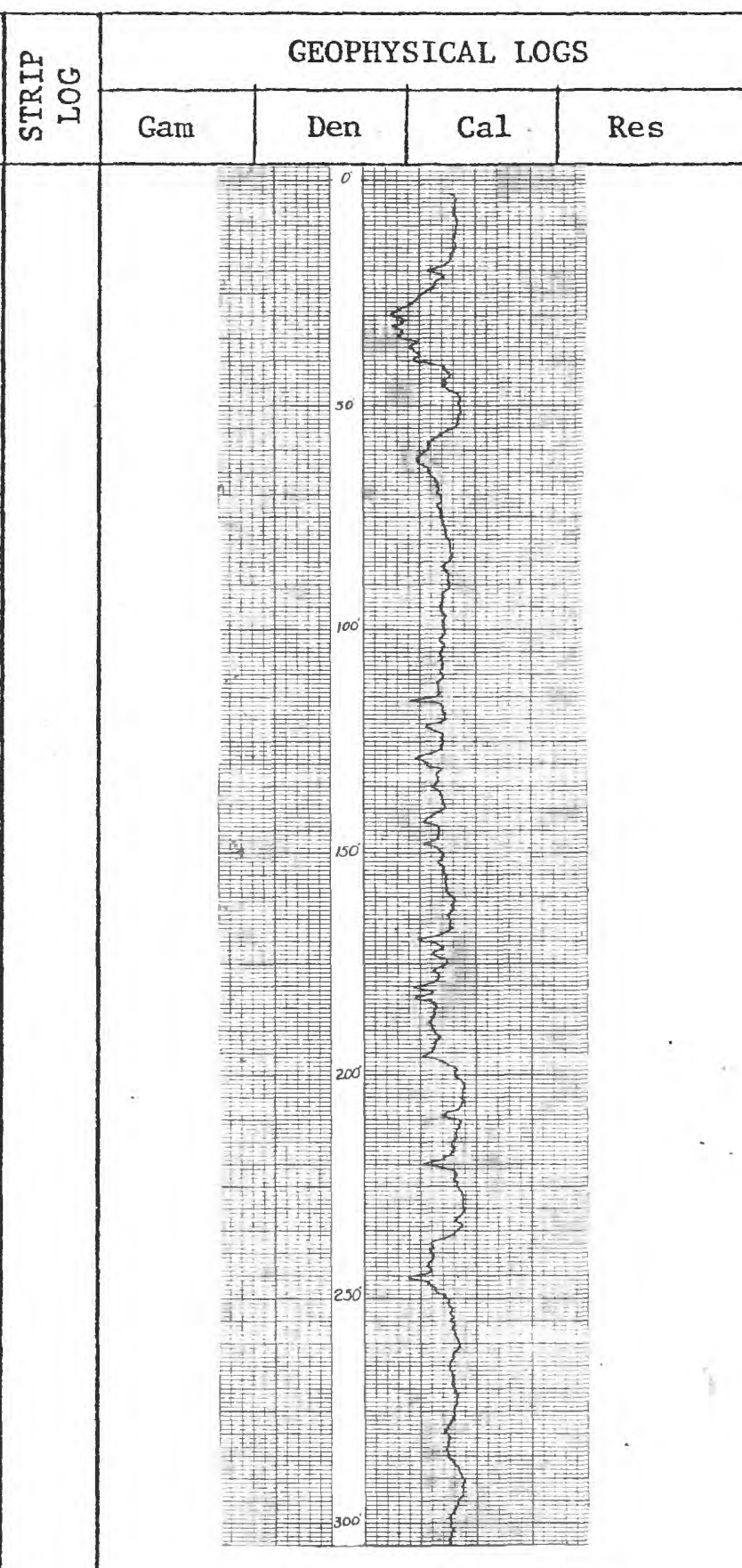




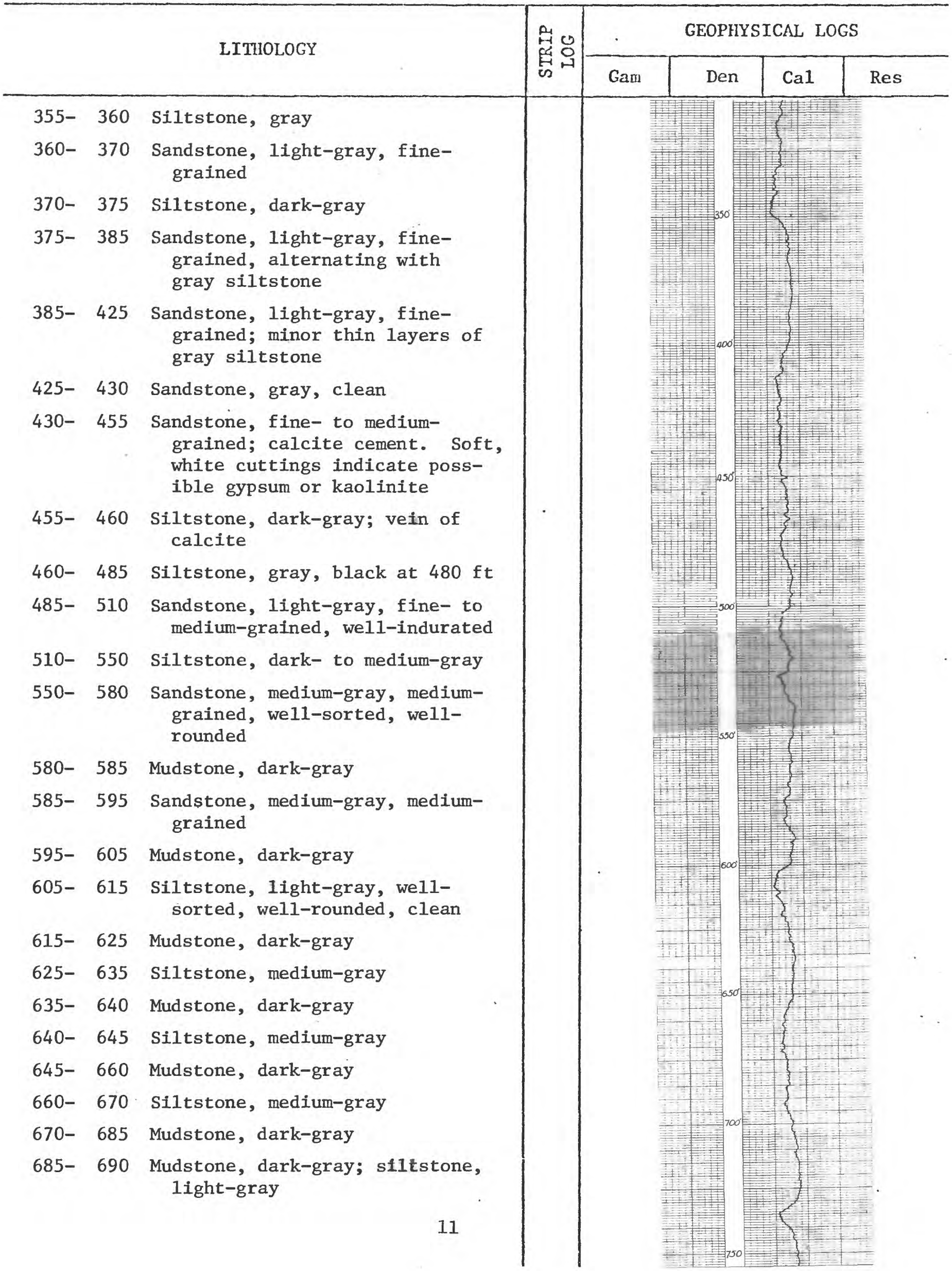




\begin{tabular}{|c|c|c|c|c|c|c|c|}
\hline & & \multirow{2}{*}{ LITHOLOGY } & \multirow{2}{*}{ 嵒 } & \multicolumn{4}{|c|}{ GEOPHYSICAL LOGS } \\
\hline & & & & Gam & Den & Cal & Res \\
\hline 690 & -695 & Mudstone, dark-gray & & & & & \\
\hline 695 & -710 & Mudstone, medium-gray & & & & & \\
\hline 710 & -745 & Mudstone, dark-gray & & & & & \\
\hline 745 & -760 & $\begin{array}{l}\text { Mudstone, dark-gray; siltstone, } \\
\text { light-gray }\end{array}$ & & & & & \\
\hline 760 & -770 & $\begin{array}{l}\text { Siltstone, light-gray, with } \\
\text { interbedded carbonaceous } \\
\text { material and some mudstone }\end{array}$ & & & & & \\
\hline $770-$ & -780 & $\begin{array}{l}\text { Sandstone, light-gray, very } \\
\text { fine grained, poorly } \\
\text { cemented }\end{array}$ & & & & & \\
\hline 780 & -795 & $\begin{array}{l}\text { Siltstone, light-gray, with } \\
\text { some carbonaceous material } \\
\text { and mudstone }\end{array}$ & & & W. & & \\
\hline 795 & -805 & Mudstone, dark-gray & & & & & \\
\hline 805 & -810 & $\begin{array}{l}\text { Sandstone, light-gray, very } \\
\text { fine grained, clean }\end{array}$ & & & & & \\
\hline 810 & -815 & Mudstone, dark-gray & & & & & \\
\hline 815 & -845 & $\begin{array}{l}\text { Siltstone, medium-gray, with } \\
\text { carbonaceous material and } \\
\text { some mudstone }\end{array}$ & & & & & \\
\hline 845 & -850 & Shale, carbonaceous & & & & & \\
\hline 850 & -875 & $\begin{array}{l}\text { Sandstone, light-gray, fine- } \\
\text { grained, interbedded with } \\
\text { carbonaceous shale }\end{array}$ & & & & & \\
\hline 875 & -880 & Shale, carbonaceous & & & 4 & & \\
\hline 880 & -890 & $\begin{array}{l}\text { Sandstone, light-gray, very } \\
\text { fine grained }\end{array}$ & & & & & \\
\hline 890 & - 918 & $\begin{array}{l}\text { Siltstone, light-gray, with } \\
\text { interbedded stringers of } \\
\text { shale and coal. Grades } \\
\text { downward to shale }\end{array}$ & & & 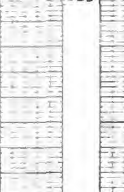 & & \\
\hline 918 & - 922 & $\begin{array}{l}\text { Shale, dark-gray; some } \\
\text { interbedded siltstone }\end{array}$ & & & & & \\
\hline 922 & - 932 & $\begin{array}{l}\text { Shale, dark-gray to black } \\
\text { TOP OF CASTLEGATE SANDSTONE }\end{array}$ & & & & & \\
\hline 932 & $-1,034$ & $\begin{array}{l}\text { Sandstone, light- to medium- } \\
\text { gray, fine-grained; shale } \\
\text { and coal stringers as much } \\
\text { as } 1 \text { in. thick; some } \\
\text { pyrite (Kc on fig. 3) }\end{array}$ & & & ind & 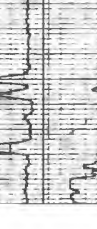 & \\
\hline & & 12 & & & & & \\
\hline
\end{tabular}




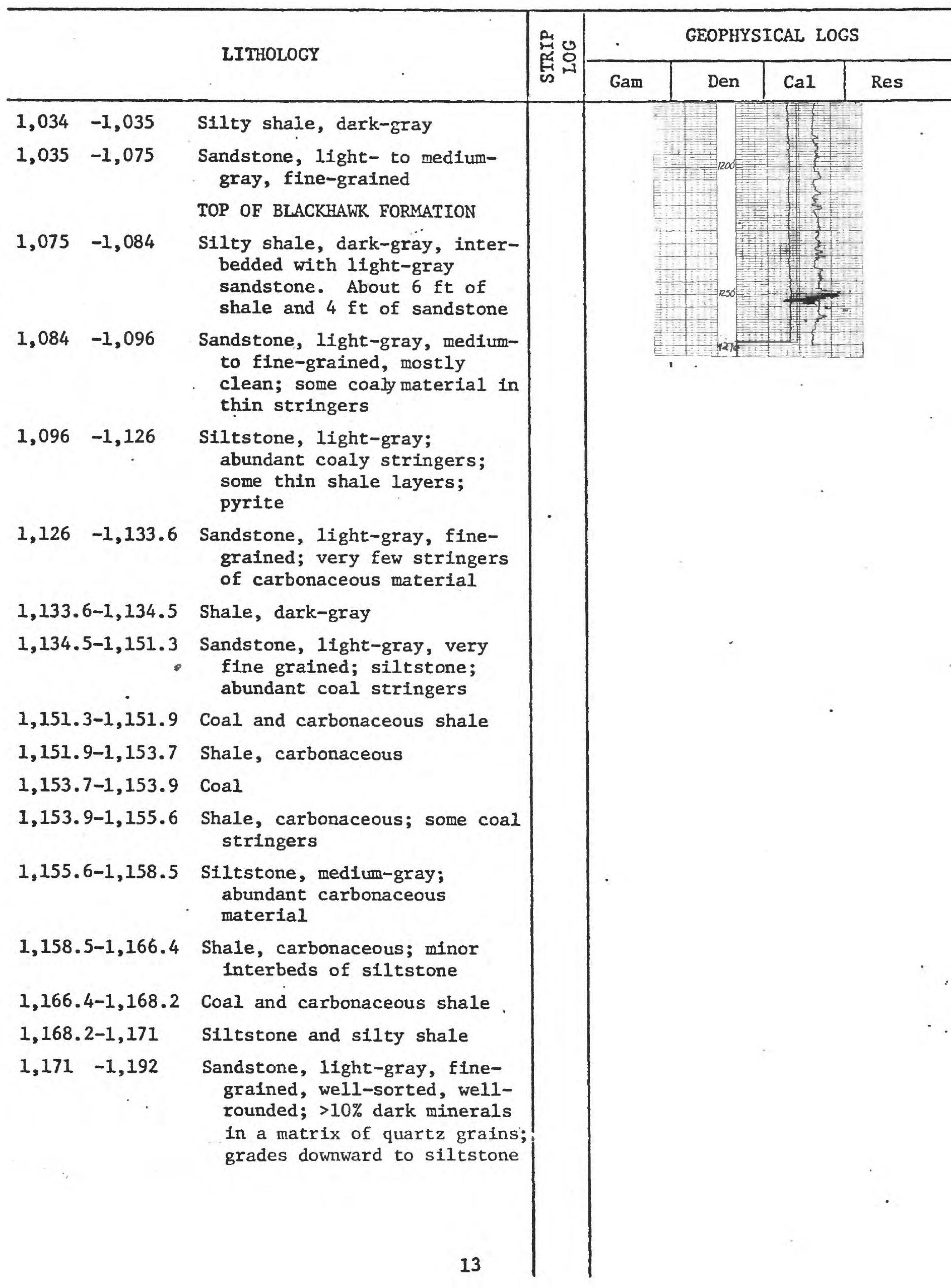




\begin{tabular}{|c|c|c|c|c|c|}
\hline \multirow{2}{*}{ LITHOLOGY } & \multirow{2}{*}{ 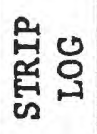 } & \multicolumn{4}{|c|}{ GEOPHYSICAL LOGS } \\
\hline & & Gam & Den & $\mathrm{Cal}$ & Res \\
\hline
\end{tabular}

1,192 -1,216.5 Siltstone, 1ight-gray, some stringers of carbonaceous material

1,216.5-1,218 Siltstone interbedded with shale

1,218 -1,237.5 Sandstone, 1ight-gray, finegrained, well-rounded, with some carbonaceous stringers; crossbedded

1,237.5-1,241 Siltstone, 1ight-gray, wellrounded, with some carbonaceous material

$1,241-1,272.6$ Siltstone with interbedded shale and carbonaceous material. $80 \%$ siltstone

Total depth: $1,272.6$ 
Hole No. BC-6-RC Quadrangle Range Creek Elevation $5,840 \mathrm{ft}$

Location: T. 17 S., R. 15 E., sec. $23,300^{\prime}$ FSL $2,000^{\prime}$ FEL

Rotary-

drilled depth 1,595'
Cored interval Logged depth 1,595'Total depth 1,595

Drilling mediun Water and foam

Geophysical logs:

Caliper (Cal) - Logging speed: 40 ft $/ \min$. Resistivity (Res):

Gamma (Gam) :

Density (Den):
T.C. 2 sec.

T.C. 1 sec.
Others: 20. $\mathrm{ft} / \mathrm{min}$

Scale: $\quad 4 \Omega / 10 g$ div.

Scale: $15 \mathrm{cps} / \mathrm{log} \mathrm{div}$

Scale: $200 \mathrm{cps} / \log \mathrm{div}$.

Remarks:

\section{LITHOLOGY}

0- 10 Alluvium

10- 60 Shale, maroon, variegated; limestone bed at $15 \mathrm{ft}$, gray; thin limestone beds throughout

60- 80 Shale, reddish-brown

80- 100 Mudstone, gray, soft

100- 120 Limestone

120- 125 Shale, reddish-brown

125- 135 Shale, gray

135- 160 Silty limestone, gray

160- 170 Shale, gray

170- 180 Shale, reddish-brown

180- 210 Limestone, white; interbedded with gray shale and mudstone

210- 250 Mudstone, gray

250- 280 Mudstone, dark-gray

280 - 300 Siltstone, gray

300- 305 Sandstone, fine-grained

305- 320 Sandstone, fine-grained; mudstone, dark-gray

320 - 325 Sandstone, fine- to medium-grained

325- 330 Sandstone, fine- to mediumgrained; mudstone, dark-gray

330- 335 Sandstone, medium-grained

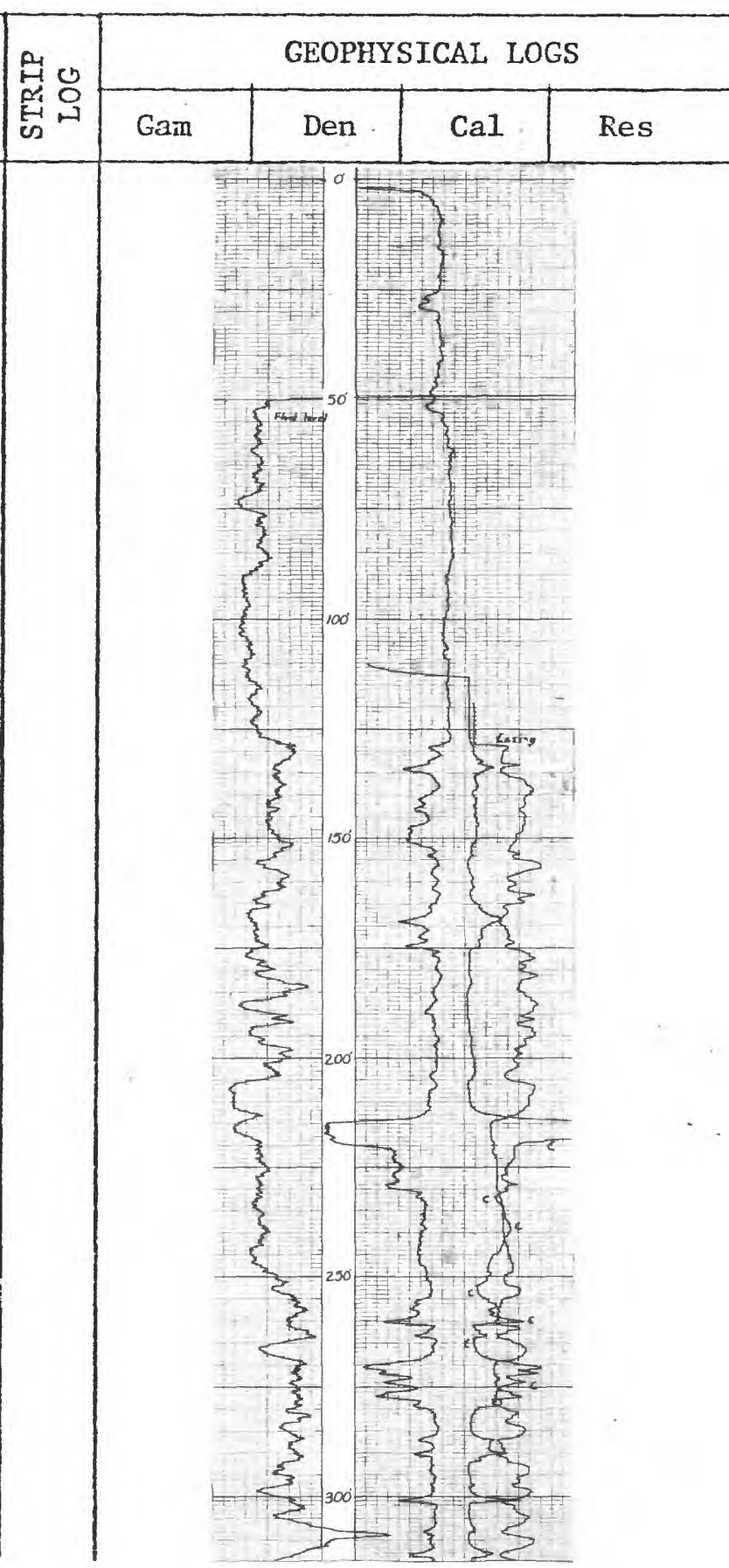




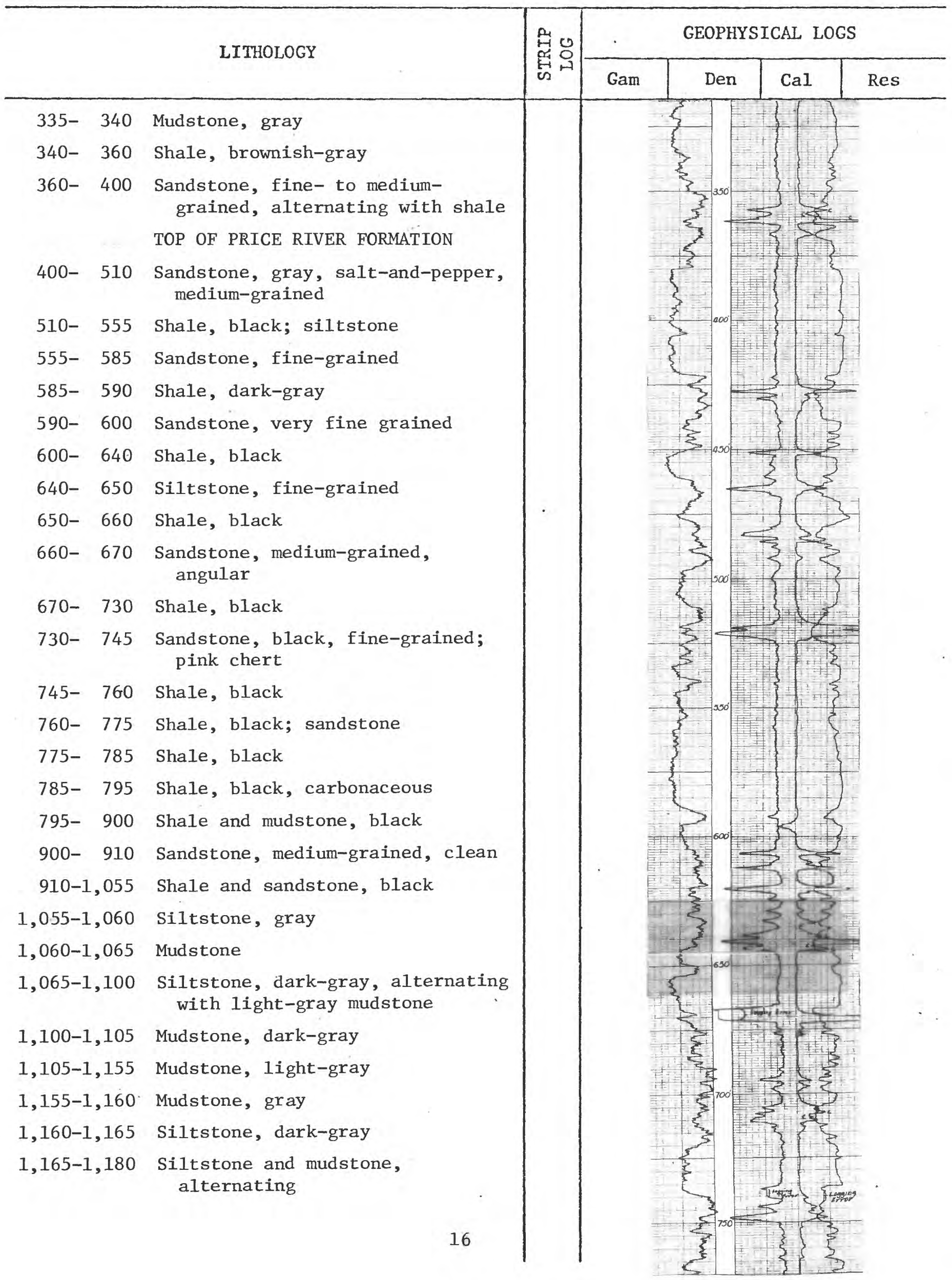




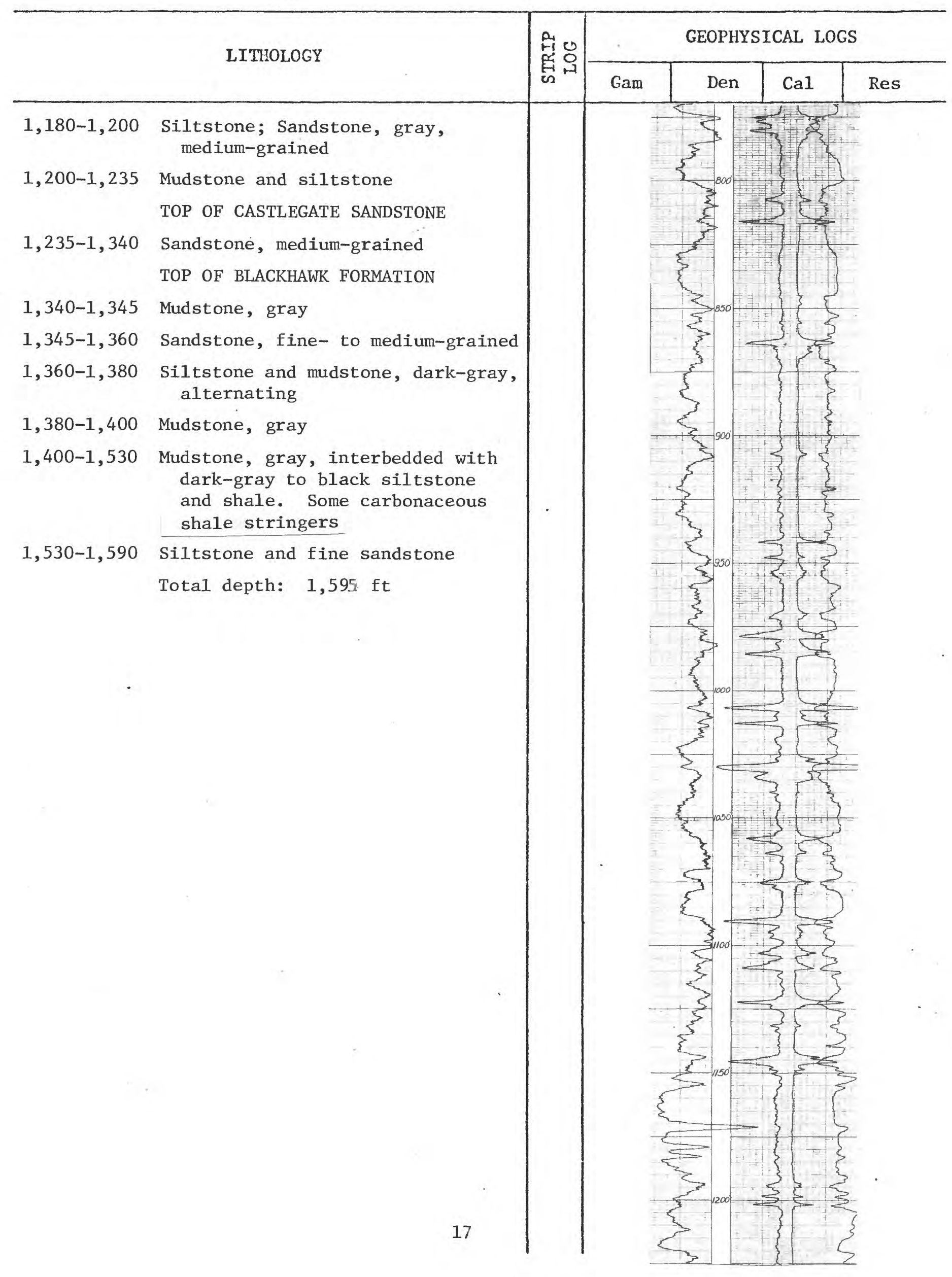


Hole No.

BC-6-RC

(continued)

LITHOLOGY

\begin{tabular}{|c|c|c|c|c|}
\hline \multirow{2}{*}{ 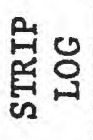 } & \multicolumn{4}{|c|}{ GEOPHYSICAL LOGS } \\
\hline & Gam & Den & $\mathrm{Cal}$ & Res \\
\hline
\end{tabular}


Hole No. BC-7-RC Quadrangle Range Creek Elevation $5,200 \mathrm{ft}$

Location: T. 17 S., R. 16 E., sec. $30,300^{\prime}$ FSL 1,200' FEL

Rotarydrilled depth $931^{\prime}$

Cored interval 931-1,083' Logged depth 1.,081' Total depth 1,083 Drilling medium Air, form, and mud

Geophysical 1ogs:

Caliper (Cal) - Logging speed: $\mathrm{ft} / \mathrm{min}$. Others: $\mathrm{ft} / \mathrm{min}$

Resistivity (Res):

Gamma (Gam) :

Density (Den):
T.C. 2 sec.

T.C. 2 sec.
Scale: $12.5 \Omega / 10 g$ div.

Scale: $20 \mathrm{cps} / \mathrm{log}$ div.

Scale: $200 \mathrm{cps} / 1 \mathrm{og}$ div.

Remarks:

\section{LITHOLOGY}

0- 30 Silty shale, dark-gray

30- 50 Sandstone, light-gray, very fine grained, poorly sorted, subangular, soft; abundant dark minerals

50- 55 Shale, medium-gray, fissile

55- 60 Siltstone, light-gray, to sandstone, very fine grained, poorly sorted, subangular, soft; abundant dark minerals

TOP OF PRICE RIVER FORMATION

60- 65 Shale, dark-gray, carionaceous

65- 70 Shale, medium-gray

70- 95 Siltstone, light-gray

95- 105 Shale, dark-gray

105- 110 Sandstone, 1ight-gray, very fine grained; shale, dark-gray

110- 125 Shale, dark-gray

125- 150 Sandstone, light-gray, very fine grained, poorly sorted, subangular, poorly cemented; abundant dark minerals

150- 185 Silty shale, dark-gray; coal, ferrous, at $170-175 \mathrm{ft}$

185- 190 Shale, dark-gray, carbonaceous; siltstone, light-gray

190- 195 Shale, black, carbonaceous; coa1

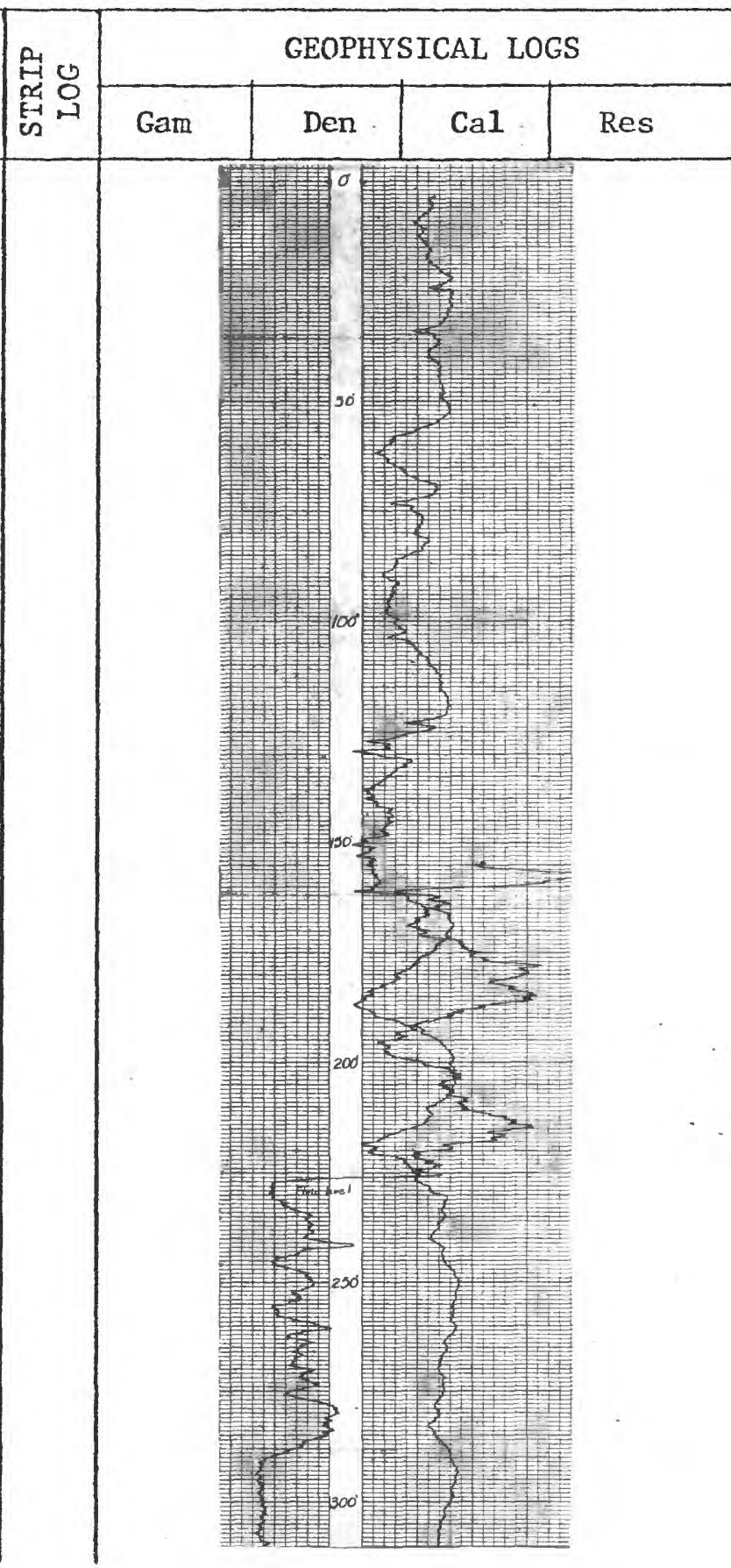




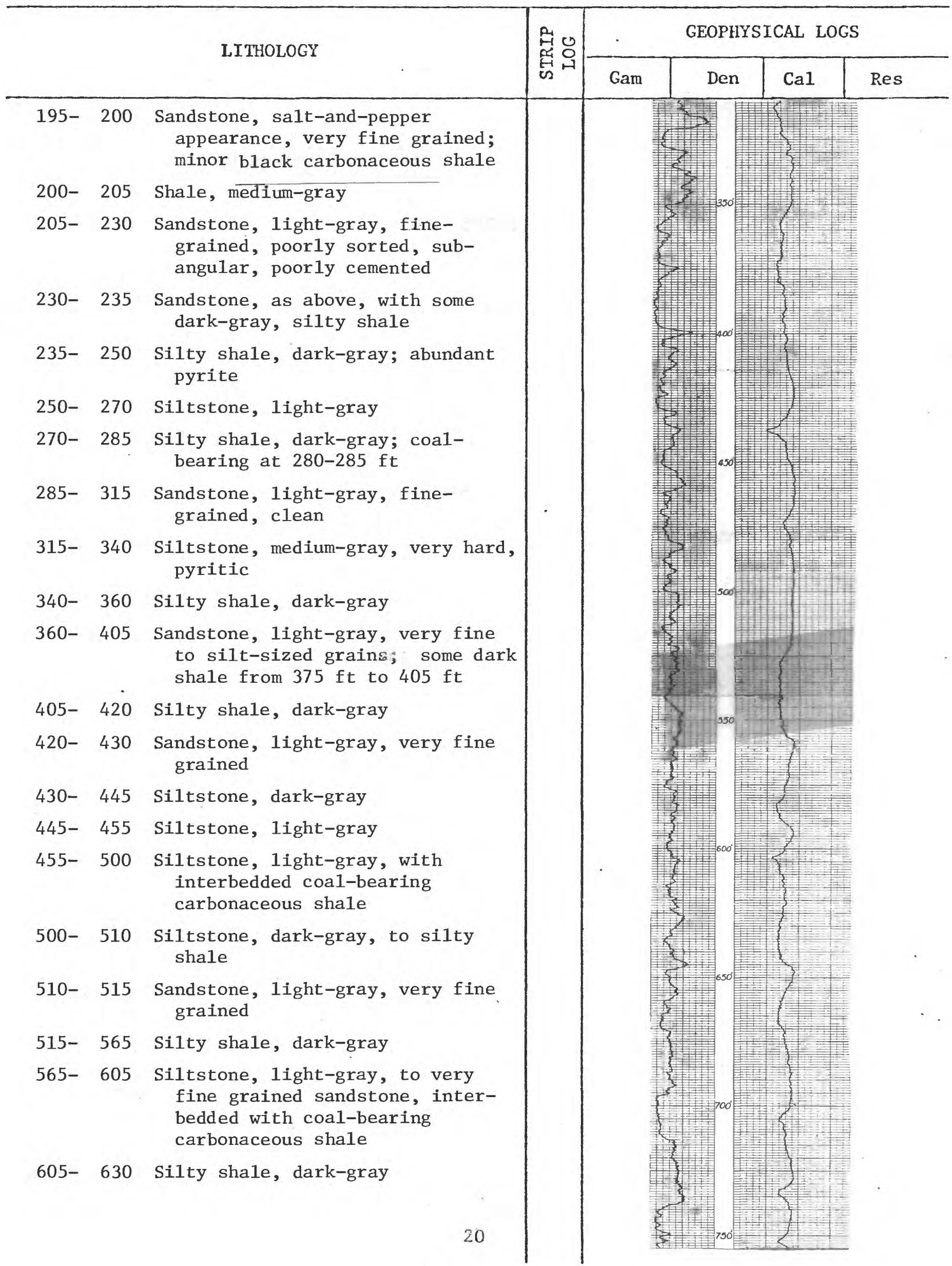


Hole No.

$\mathrm{BC}-7-\mathrm{RC}$

(continued)

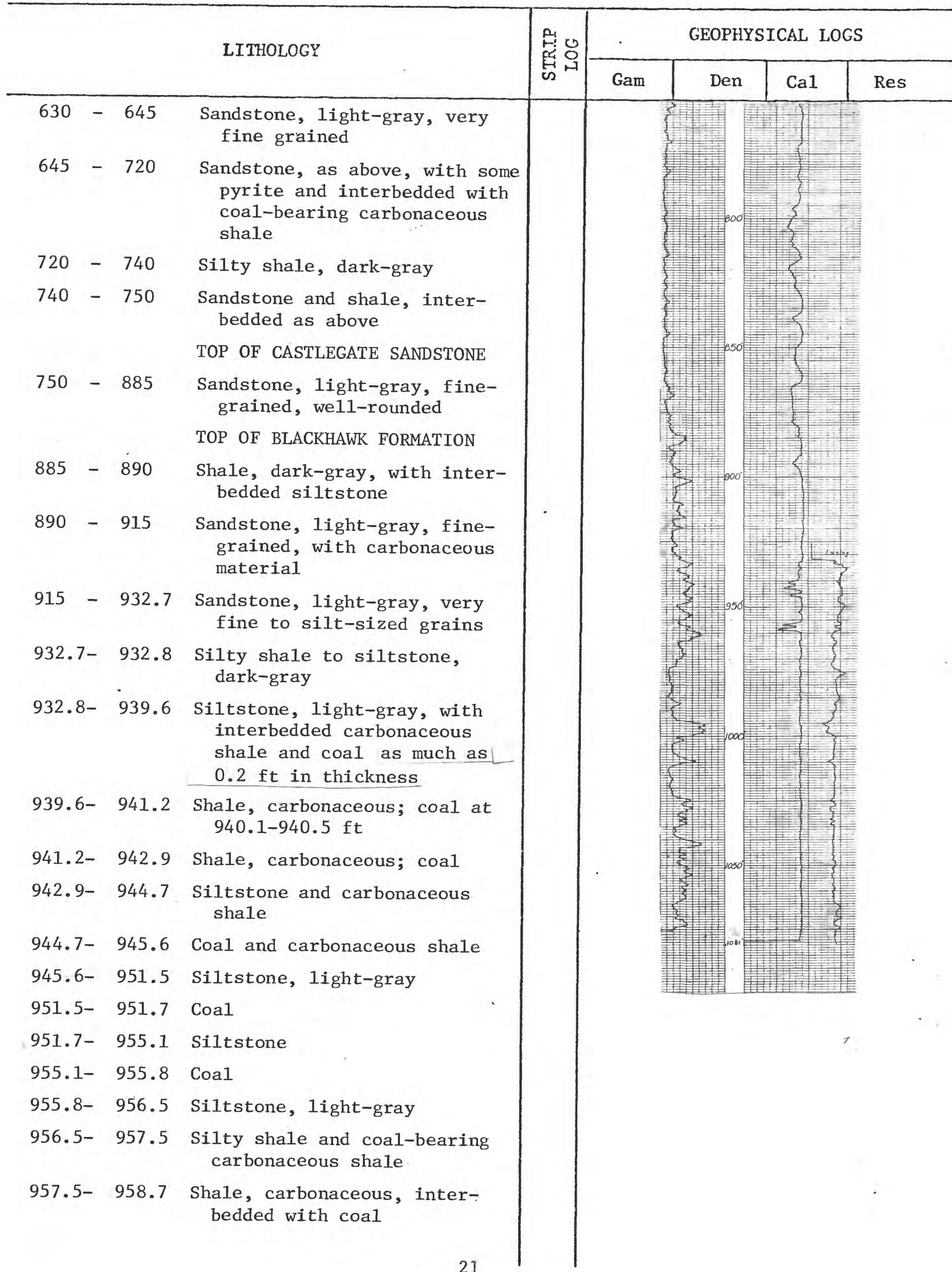




\begin{tabular}{|c|c|c|c|c|c|}
\hline \multirow{2}{*}{ LITHOLOGY } & \multirow{2}{*}{ 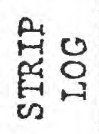 } & \multicolumn{4}{|c|}{ GEOPHYSICAL LOGS } \\
\hline & & Gam & Den & $\mathrm{Ca} 1$ & Res \\
\hline
\end{tabular}

958.7- 962.8 Silty shale, dark-gray

962.8- 964.1 Siltstone, 1ight-gray

964.1- 973 Sandstone, medium-gray, finegrained; abundant dark minerals; deformation structures present

973 - 994.8 Sandstone, light-gray, massive, with some crossbedding

994.8- 998.6 Shale, dark-gray; some carbonaceous material, interbedded with siltstone

998.6-1,083 Sandstone, light-gray, finegrained; interbedded shales as much as $0.3 \mathrm{ft}$ thick at top, $0.5 \mathrm{ft}$ thick in the middle, and $0.1 \mathrm{ft}$ thick at the bottom; some carbonaceous material

Total depth: 1,083 ft 
Hole No. BC-8-RC Quadrangle Range Creek Elevation $4,950 \mathrm{ft}$

Location: T. 17 S., R. 16 E., sec. $33, \underline{700^{\prime}}$ FWL 200' FNL

Rotarydrilled depth $1,020^{\prime}$
Cored interval 0

Drilling medium Water and foam

Geophysical logs:

Caliper (Cal) - Logging speed: $40 \mathrm{ft} / \mathrm{min}$. Others: 20. $\mathrm{ft} / \mathrm{min}$

Resistivity (Res):

Gamma (Gam):

Density (Den):
T.C. 2 sec.

T.C. 2 sec.
Scale:

Scale: $15 \mathrm{cps} / 1 \mathrm{log}$ div.

Scale: $140 \mathrm{cps} / 1 \mathrm{log}$ div.

Remarks: Resistivity scale not shown on $10 \mathrm{~g}$

\section{LITHOLOGY}

0- 15 Alluvium
$15-16 \begin{aligned} & \text { Shale, dark, carbonaceous; coal } \\ & \text { streaks }\end{aligned}$
$16-20$ Shale, gray to brown
$20-30$ Sandstone, dark-gray, fine-grained,
slightly carbonaceous

\begin{tabular}{|c|c|c|c|c|}
\hline \multirow{2}{*}{$\begin{array}{l}\text { 嵒 } \\
\text { 出 } \\
\text { 舁 }\end{array}$} & \multicolumn{4}{|c|}{ GEOPHYSICAL LOGS } \\
\hline & Gam & Den & $\mathrm{Cal}$ & Res \\
\hline
\end{tabular}




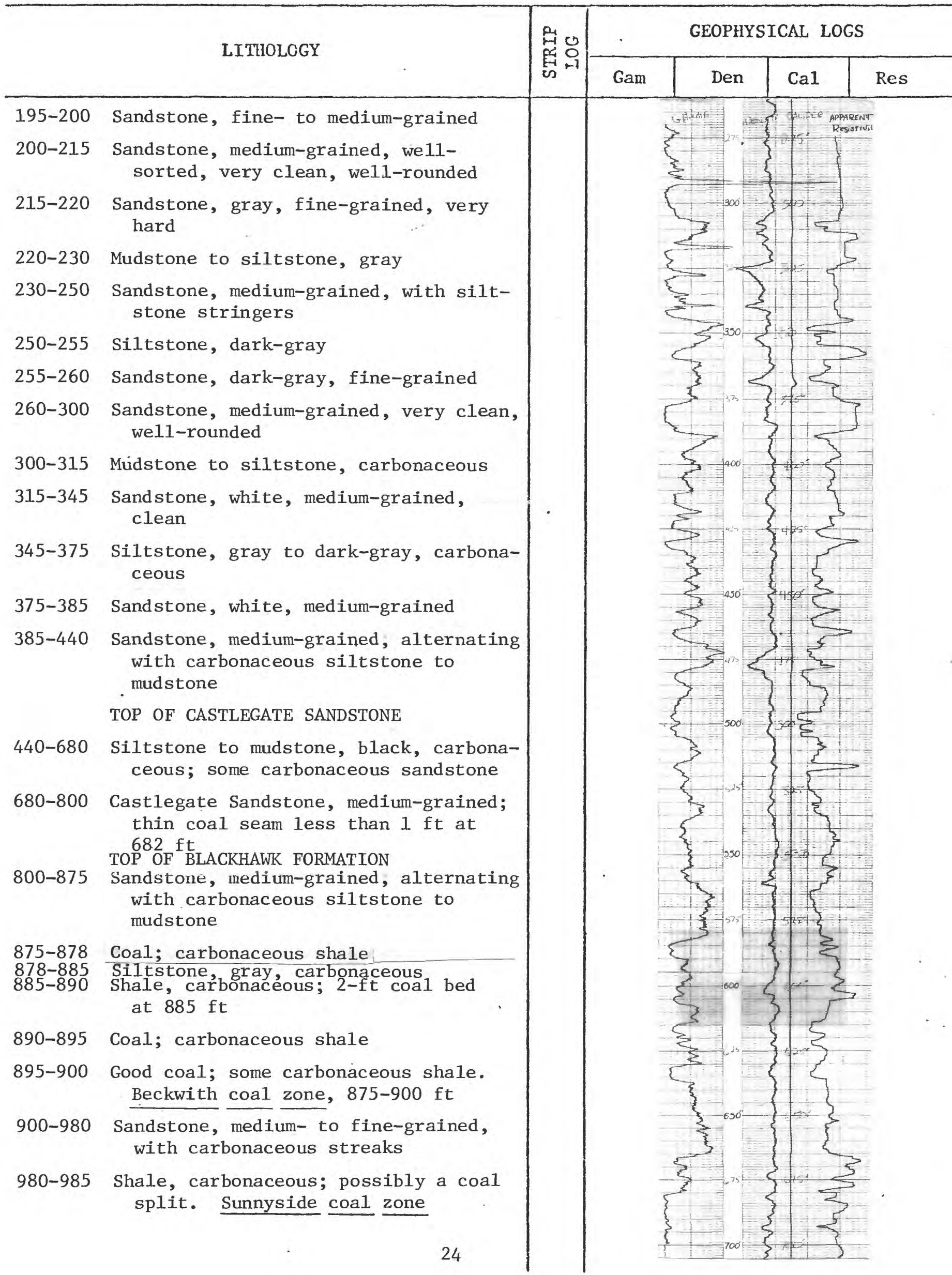


Hole No.

$\mathrm{BC}-8-\mathrm{RC}$

(continued)

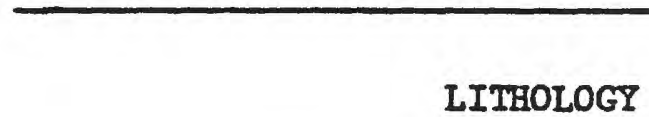

985-1,020 Sandstone, fine-grained, carbonaceous

Total depth: 1,020 
Hole No. BC-9-RC Quadrangle Range Creek Elevation $4,760 \mathrm{ft}$

Location: T. 17 S., R. 16 E., sec. $27,950^{\prime}$ FWL $1,950^{\prime}$ FNL

Rotarydrilled depth $1,224 \mathrm{ft}$
Cored interval

Drilling medium Logged depth $1,222^{\prime}$ 'Total depth $1,224^{\prime}$

Geophysical logs:

Caliper (Cal) - Logging speed: $40 \mathrm{ft} / \mathrm{min}$. Resistivity (Res):

Gamma (Gam):

Density (Den):
T.C. $\frac{2}{2} \mathrm{sec}$.

T.C. 2 sec.
Others: $20 . \mathrm{ft} / \mathrm{min}$

Scale: $14.3 \Omega / 1 \log$ div.

Scale: $15 \mathrm{cps} / \mathrm{log} \mathrm{div}$.

Scale: $125 \mathrm{cps} / \log \mathrm{div}$.

Remarks: Collared $400 \mathrm{ft}$ below top of Price River Formation

\begin{tabular}{|c|c|c|c|c|c|c|c|}
\hline \multirow{2}{*}{\multicolumn{3}{|c|}{ LITHOLOGY }} & \multirow{2}{*}{ 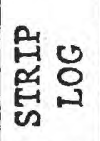 } & \multicolumn{4}{|c|}{ GEOPHYSICAL LOGS } \\
\hline & & & & Gam & Den & $\mathrm{Cal}$ & Res \\
\hline $0-$ & 55 & Alluvium & & & & & \\
\hline $\begin{array}{c}55- \\
.\end{array}$ & 85 & $\begin{array}{l}\text { Sandstone, 1ight-gray, fine- } \\
\text { grained; interbedded gray } \\
\text { mudstone }\end{array}$ & & & & & \\
\hline $85-$ & 115 & Mudstone, dark-gray & & & & & \\
\hline $115-$ & 135 & $\begin{array}{l}\text { Mudstone, medium- to dark-gray, } \\
\text { with some interbedded sand- } \\
\text { stone }\end{array}$ & & & & & \\
\hline $135-$ & 140 & $\begin{array}{l}\text { Sandstone, 1ight-gray, medium- } \\
\text { grained }\end{array}$ & & & & & \\
\hline $140-$ & 160 & $\begin{array}{l}\text { Sandstone, medium-gray, medium- } \\
\text { to fine-grained; rare mudstone } \\
\text { partings }\end{array}$ & & & & & \\
\hline $160-$ & 220 & Mudstone, dark-gray & & & & & \\
\hline $220-$ & 225 & $\begin{array}{l}\text { Sandstone, light-gray, medium- } \\
\text { grained }\end{array}$ & & & & & \\
\hline $225-$ & 245 & $\begin{array}{l}\text { Sandstone, light-gray, medium- } \\
\text { grained, with some mudstone } \\
\text { partings }\end{array}$ & & & & & . \\
\hline $245-$ & 260 & $\begin{array}{l}\text { Sandstone, gray, medium- to } \\
\text { coarse-grained }\end{array}$ & & & & & \\
\hline $260-$ & 270 & Mudstone, dark-gray & & & & & \\
\hline $270-$ & 290 & $\begin{array}{l}\text { Sandstone, light-gray, we11- } \\
\text { sorted, medium- to fine- } \\
\text { grained }\end{array}$ & & & & & \\
\hline $290-$ & 295 & Sandstone, medlum-grained & & & & & \\
\hline $295-$ & 305 & $\begin{array}{l}\text { Mudstone, dark-gray, carbona- } \\
\text { ceous }\end{array}$ & & & & & \\
\hline
\end{tabular}




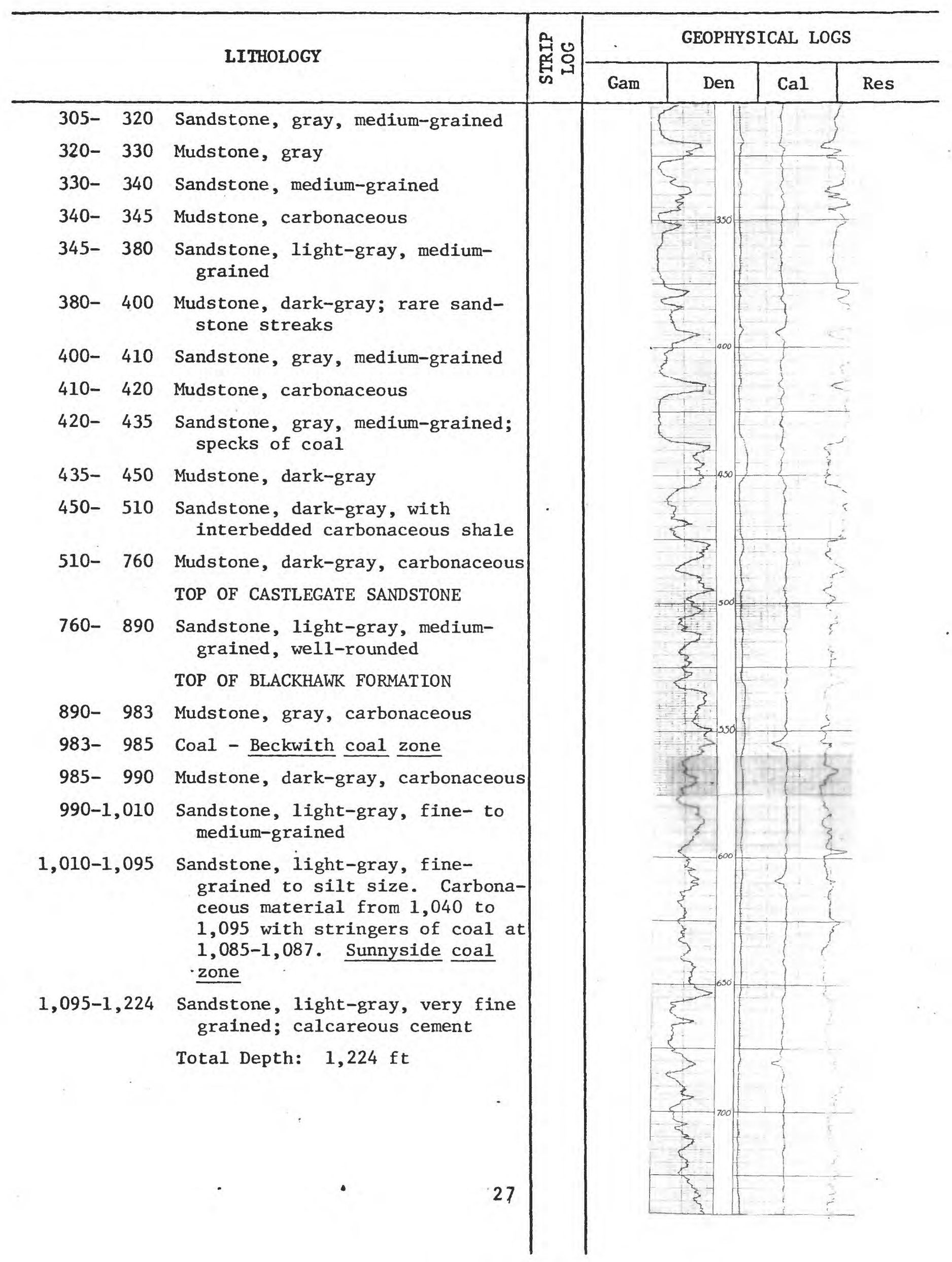


Hole No.

BC-9-RC

(continued)

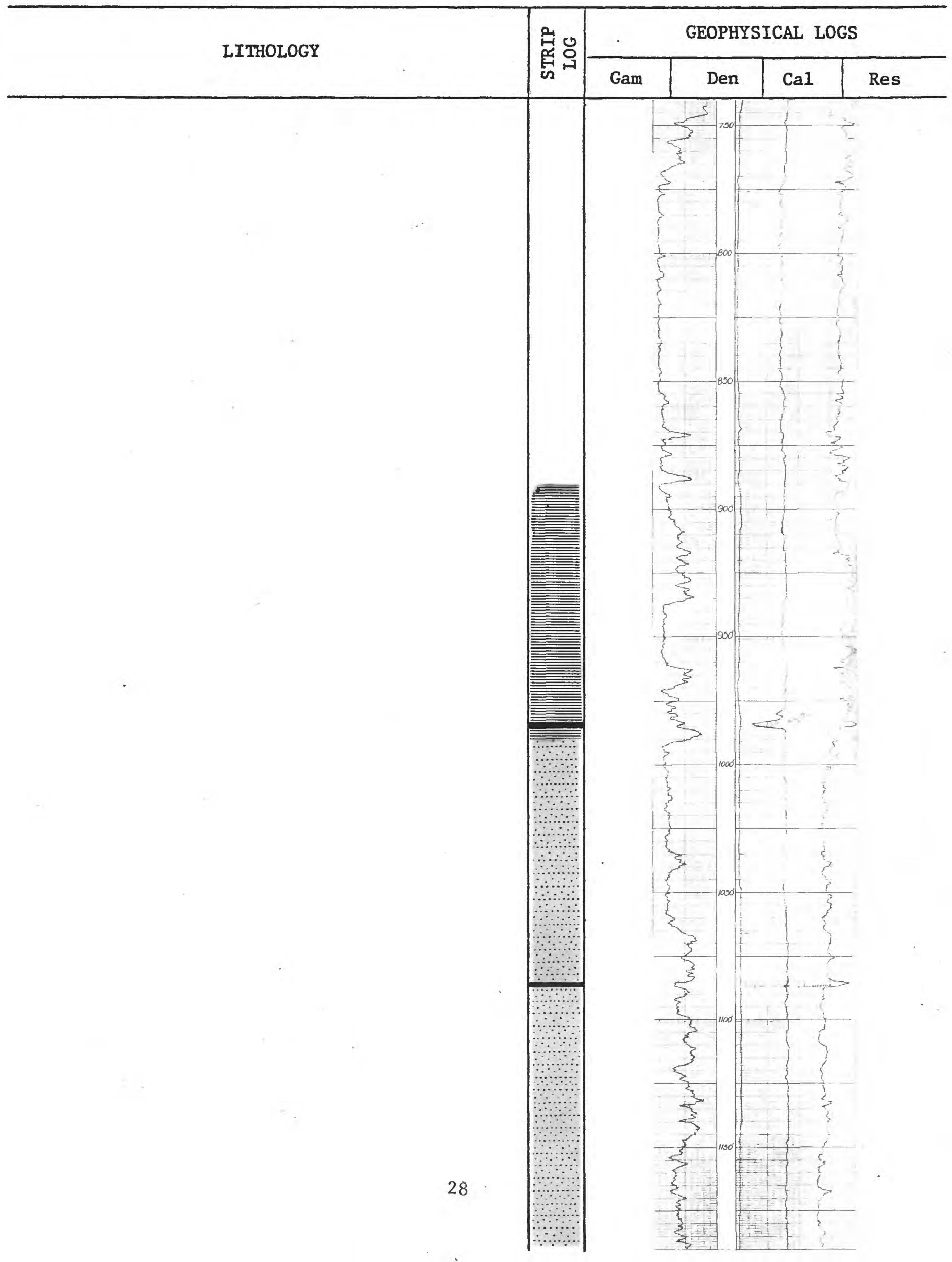


Hole No. BC-9-RC (continued)

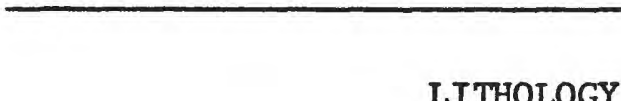

LITHOLOGY

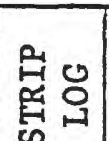

욤업
. GEOPHYSICAL LOGS

\begin{tabular}{|l|l|l|l}
\hline Gam & Den & Cal & Res \\
\hline
\end{tabular}


U.S. GEOLOGICAL SURVEY

DRILL-HOLE LOG, EMERY COUNTY, UTAH

Hole No. BC-2-W Quadrangle Woodside Elevation $6,150 \mathrm{ft}$

Location: T. 17 S., R. 15 E., sec. 18, 1,500'FNL 2,100' FEL

Rotarydrilled depth $740^{\prime}$
Cored Interval Logged depth 738' Total depth $740^{\prime}$ Drilling medium Air, foam, and water

Geophysical logs:

$\begin{array}{lll}\text { Caliper (Cal) - Logging speed: } \frac{40 \mathrm{ft} / \mathrm{min} .}{} & \begin{array}{l}\text { Others: } \frac{20 \mathrm{ft} / \mathrm{min}}{10 \Omega / 10 \mathrm{div} .} \\ \text { Resistivity (Res): }\end{array} \\ \begin{array}{lll}\text { Gamma (Gam): } & \text { T.C. } \frac{1}{1} \mathrm{sec} . & \text { Scale: } \frac{20 \mathrm{cps} / 1 \mathrm{log} \mathrm{div} .}{200 \mathrm{cps} / 1 \mathrm{og} \mathrm{div} .} \\ \text { Density (Den): } & \text { T.C. } \frac{\mathrm{sec} .}{\text { Scale: }}\end{array}\end{array}$

Remarks: No lithologic $\log$ on this hole

\begin{tabular}{|c|c|c|c|c|}
\hline \multirow{2}{*}{ 藏怘 } & \multicolumn{4}{|c|}{ GEOPHYSICAL LOGS } \\
\hline & Gam & Den & Cal & Res \\
\hline
\end{tabular}


Hole No.

$\mathrm{BC}-2-\mathrm{W}$

(continued)

LITHOLOGY

\begin{tabular}{|c|c|c|c|c|}
\hline \multirow{2}{*}{ 䓛号 } & \multicolumn{4}{|c|}{ GEOPHYSICAI LOGS } \\
\hline & Gam & Den & Cal & Res \\
\hline
\end{tabular}

702-718 Coa1 
Hole No. BC-3-W

Quadrangle Woodside Elevation $6,400 \mathrm{ft}$

Location: T. 17 S., R. 15 E., sec. $\frac{15}{955 . T-}$, 350' FNL 2,100' FWL

Rotarydrilled depth $955.7^{\prime}$

Cored interval $1,212 \mathrm{ft}$ Logged depth $1,212^{\text {Total depth } 1,212}$ Drilling medium Air, foam, and mud

Geophysical 1ogs:

Caliper (Cal) - Logging speed: $40 \mathrm{ft} / \mathrm{min}$. Resistivity (Res):

Gamma (Gam):

T.C. sec.

Density (Den):

T.C. sec.

$\begin{array}{ll}\text { Others: } & \frac{20 . \mathrm{ft} / \mathrm{min}}{16.7 \Omega / \log \mathrm{div} .} \\ \text { Scale: } & \frac{15 \mathrm{cps} / \log \mathrm{div} .}{200 \mathrm{cps} / \log \mathrm{div} .} \\ \text { Scale: }\end{array}$

Remarks:

Time constant not indicated.

Subtract $2 \mathrm{ft}$. from geophysical $10 \mathrm{~g}$ depths.

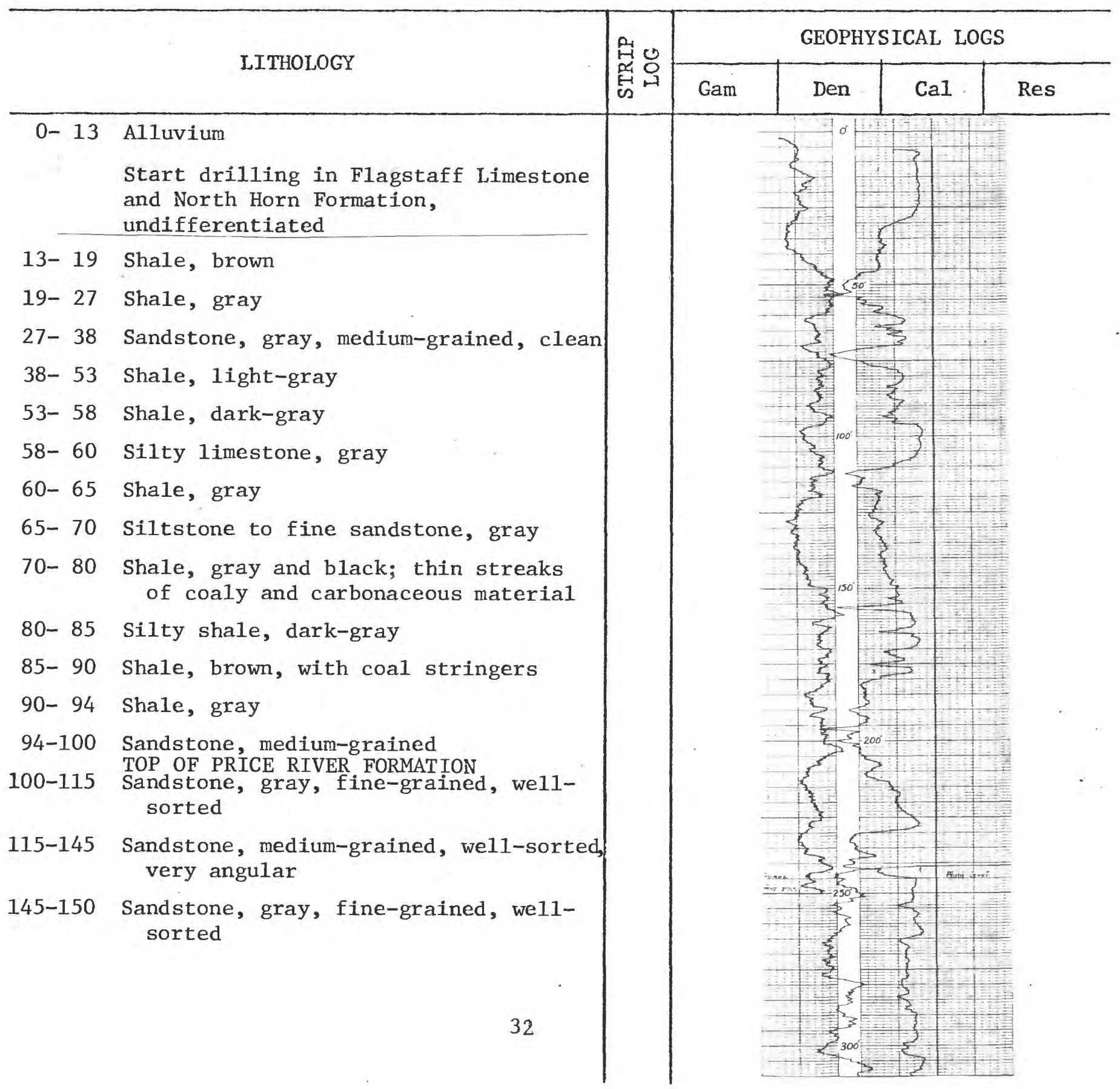


Hole No. BC-3-W (continued)

\section{LITHOLOGY}

150-155 Sandstone, dark-gray, medium-grained

155-165 Sandstone, light-gray, fine- to medium-grained

165-170 Sandstone, dark-gray, fine-grained

170-205 Sandstone, fine-grained, well-sorted; finely disseminated coal at $190 \mathrm{ft}$

205-230 Sandstone, light-gray, medium-grained

230-250 Sandstone, dark-gray, fine-grained; finely disseminated coal at $240 \mathrm{ft}$

250-260 Sandstone, light-gray, fine- to medium-grained

260-275 Sandstone, light-gray, medium-grained

275-300 Sandstone, dark-gray, fine-grained

300-310 Shale, Gray

310-320 No samples

320-325 Shale, gray

325-360 Sandstone, medium-grained

360-380 Sandstone, medium- to coarse-grained, fairly clean; carbonaceous material from about 370 to $380 \mathrm{ft}$

380-410 Sandstone, medium-grained, with interbedded carbonaceous siltstone

410-445 Sandstone, white, medium-grained, well-sorted, very clean

445-465 Sand stone, brown, medium-grained, with carbonaceous shale

465-480 Sandstone, fine-grained to silty, carbonaceous; interbedded with darkgray mudstone to shale

480-500 Sandstone, medium-grained, with carbonaceous shale partings

500-505 Shale, red to gray, with gray siltstone

505-510 Shale, carbonaceous, with some thin coal stringers

510-520 Siltstone, dark-gray

520-530 Sandstone, medium-grained, we11rounded

530-540 Sandstone, medium-grained, with carbonaceous siltstone

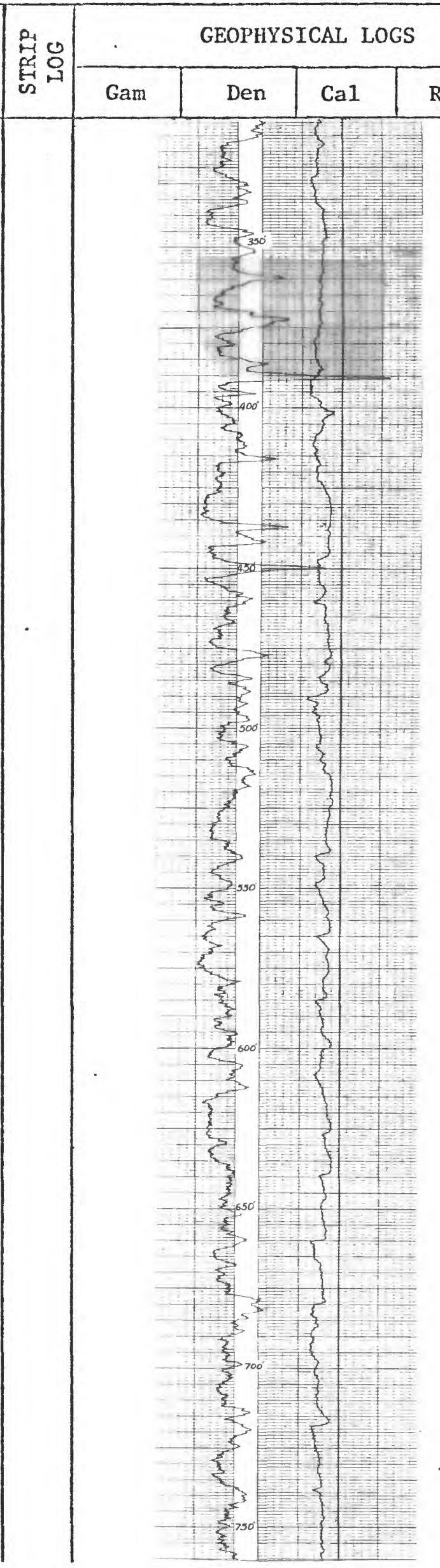


Hole No. (continued)

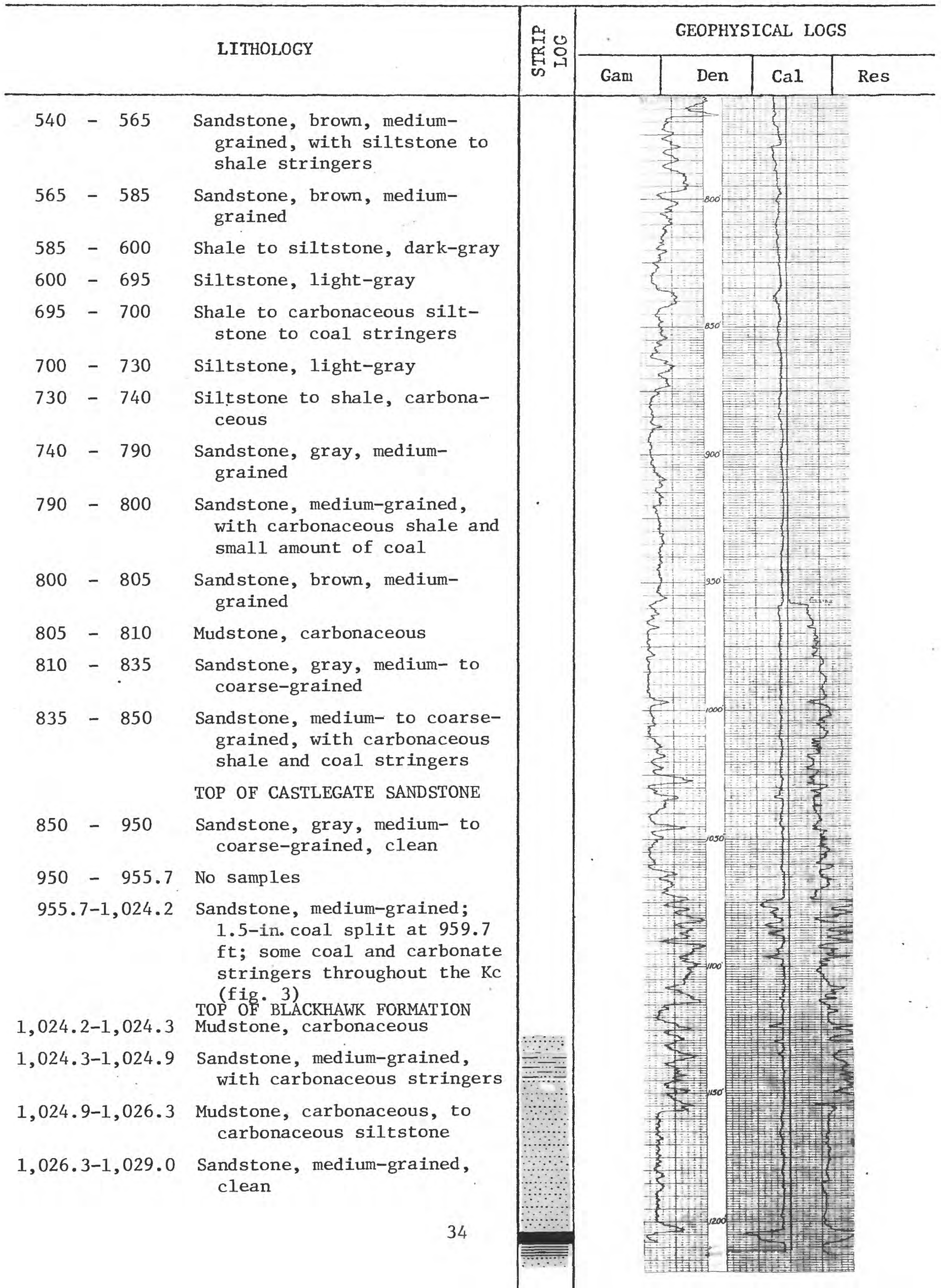




\begin{tabular}{|c|c|c|c|c|c|}
\hline \multirow{2}{*}{ LITHOLOGY } & \multirow{2}{*}{ 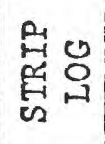 } & \multicolumn{4}{|c|}{ GEOPHYSICAL LOGS } \\
\hline & & Gam & Den & $\mathrm{Cal}$ & Res \\
\hline
\end{tabular}

1,029.0-1,031.3 Sandstone, medium-grained, with coal and carbonaceous stringers

1,031.3-1,031.8 Mudstone, carbonaceous, with coaly material at $1,031.3-$ $1,031.6 \mathrm{ft}$

1,031.8-1,032.2 Mudstone, carbonaceous

1,032.2-1,036.5 Sandstone, fine-grained, with carbonaceous stringers and some thin coal stringers $1 / 8$ in. in thickness

1,036.5-1,041.8 Sandstone, medium-grained, fairly clean

1,041.8-1,042.9 Sandstone, medium-grained, with carbonaceous stringers

1,042.9-1,043.4 Mudstone, carbonaceous, with coal stringers and resin nodules

1,043.4-1,044.3 Siltstone, carbonaceous

1,044.3-1,047.3 Sandstone, medium-grained; two carbonaceous stringers at $1,047 \mathrm{ft}$

1,047.3-1,047.7 Siltstone, carbonaceous

1,047.7-1,051.8 Sandstone, medium-grained, clean

1,051.8-1,061.8 Sandstone, medium-grained, clean, with carbonaceous stringers in lower 2 in.

1,061.8-1,070.9 Sandstone, medium-grained, with carbonaceous stringers throughout

1,070.9-1,071.9 Siltstone, dark-gray, with carbonaceous stringers at $1,071.9 \mathrm{ft}$

1,071.9-1,072.9 Coal and carbonaceous shale

1,072.9-1,073 Mudstone, carbonaceous

$1,073-1,074.7$ Coal and carbonaceous shale

1,074.7-1,076.2 Shale, carbonaceous, with coal stringers 


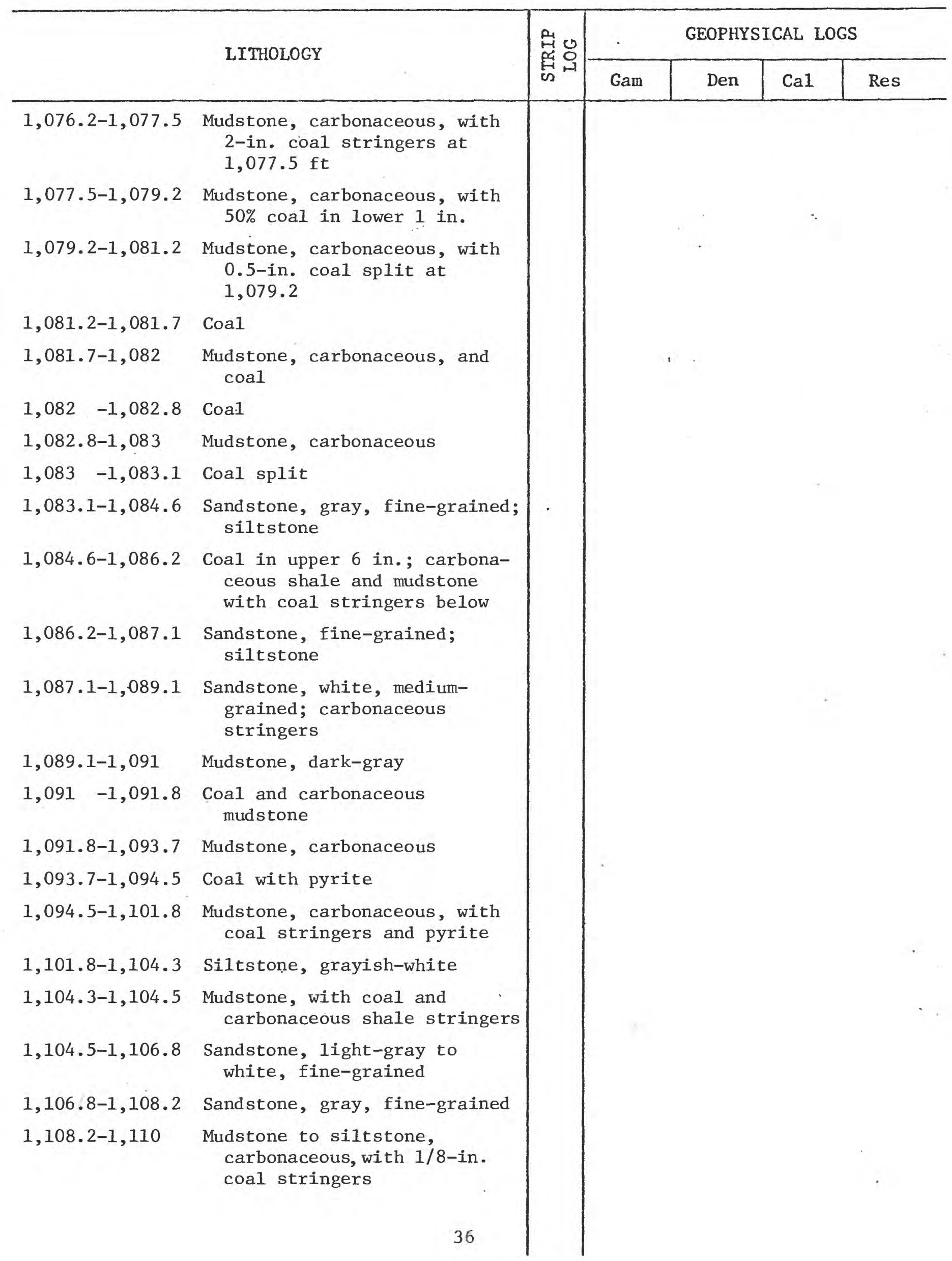




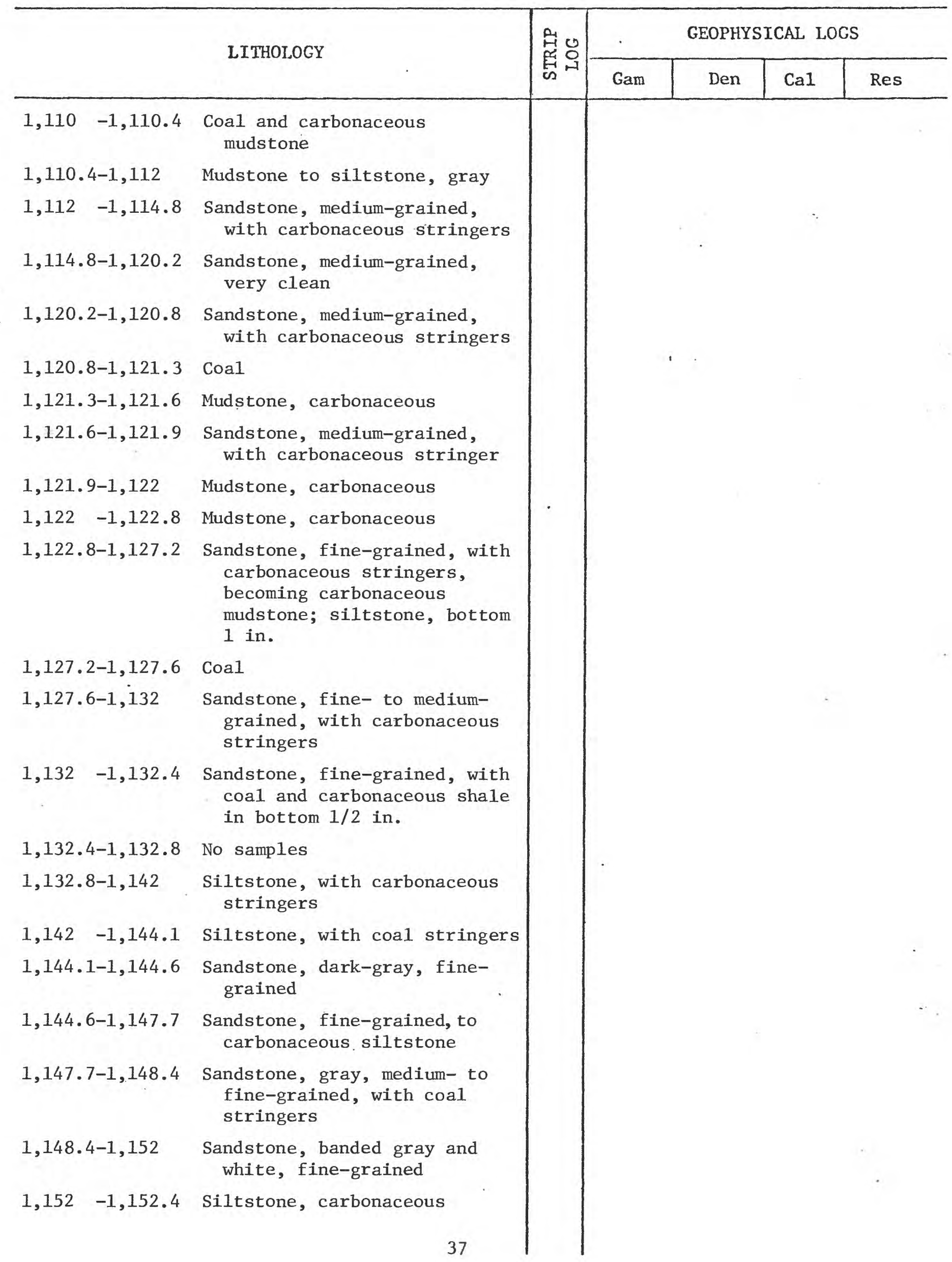




\begin{tabular}{|c|c|c|c|c|c|}
\hline \multirow[t]{4}{*}{ LITHOLOGY } & \multirow{4}{*}{ 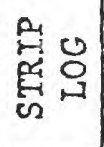 } & \multirow{2}{*}{\multicolumn{4}{|c|}{ GEOPHYSICAL LOGS }} \\
\hline & & & & & \\
\hline & & & & & \\
\hline & & Gam & Den & $\mathrm{Cal}$ & Res \\
\hline
\end{tabular}

1,152.4-1,154.5 Sandstone, fine- to mediumgrained; carbonaceous stringers

1,154.5-1,199.7 Sandstone, medium-grained, very clean

1,199.7-1,199.9 Shale, carbonaceous; coal

1,199.9-1,201.8 Mudstone, carbonaceous

$1,201.8-1,201.9$ Coa 1

1,201.9-1,205.9 Coal. Sunnyside coal zone

1,205.9-1,208.3 Mudstone, carbonaceous; some coal stringers

1,208.3-1,210.2 Mudstone, carbonaceous; interbedded with sandstone, fine-grained

1,210.2-1,212 Sandstone, fine-grained, with carbonaceous mudstone stringers

Total depth:1,212 ft 
Hole No. BC-5-W Quadrangle Woodside Elevation $6,540 \mathrm{ft}$

Location: T. 17 S., R. 15 E., sec. $21,100^{\prime}$ FNL 2,200' FWL

Rotarydrilled deptin 1,750'
Cored interval

Drilling medium Logged depth 1,722 'Total depth 1,750 Air and foam

Geophysical logs:

Caliper (Cal) - Logging speed: 40 $\mathrm{ft} / \mathrm{min}$.

Resistivity (Res):

Gamna (Gam):

T.C.

Density (Den):

T.C. sec. sec.

Remarks: Time constant not indicated

\section{LITHOLOGY}

Drilling in Flagstaff Limestone and North Horn Formation, undifferentiated

$0-5$ Shale, maroon and light-gray to white

5- 10 Limestone

10- 15 Sandstone, white, fine-grained

15- 25 Limestone, white

25- 30 Sandstone, white to 1ight-gray, fineto medium-grained

30- 75 Limy siltstone, gray; gray shale at $45 \mathrm{ft}$

75- 80 Siltstone to shale, maroon

80- 85 Siltstone, gray

85-180 Limy siltstone to limestone, gray

180-185 Limestone, white, chalky

185-230 Limy siltstone, gray

230-250 Sandstone, fine-grained

250-255 Shale to siltstone, gray to dullbrown

255-260 Shale, light-maroon

260-265 Siltstone to shale, gray

265-275 Sandstone, white, fine-grained

275-280 Siltstone to shale, dark-gray

280-310 Limy siltstone, gray

310-345 Sandstone, medium-grained, wel1rounded; dark minerals at $345 \mathrm{ft}$.

\begin{tabular}{|c|c|c|c|c|}
\hline \multirow{2}{*}{ 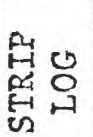 } & \multicolumn{4}{|c|}{ GEOPHYSICAL LOGS } \\
\hline & Gam & Den & $\mathrm{Cal}$ & Res \\
\hline
\end{tabular}


Hole No.

$\mathrm{BC}-5-\mathrm{W}$

(continued)

LITHOLOGY

345- 365 Siltstone to shale, white to gray

365- 385 Sandstone, medium- to coarsegrained, very well rounded

385- 390 Sandstone, dark-gray

390- 430 Sandstone, medium- to coarsegrained

430- 435 Siltstone, gray

435- 445 Sandstone, fine-grained

445- 455 Sandstone, medium-grained, we11rounded

455- 470 Shale, brownish-gray

470- 485 Sandstone, very fine grained

485- 510 Mudstone, light-gray

510- 540 Siltstone, light-gray

540- 610 Mudstone, gray TOP OF PRICE RIVER FORMATION

610- 670 Sandstone, fine-grained

670- 735 Mudstone, dark-gray

735- 770 Sandstone to siltstone

770- 790 Shale, gray, silty

790- 815 Sandstone, very fine grained

815-1,110 Shale, dark-gray, silty; some sandstone, medium-grained

1,110-1,170 Sandstone, fine-grained; shale

1,170-1,180 Shale, dark-gray

1,180-1,200 Sandstone, fine-grained

1,200-1,270 Shale, dark-gray

1,270-1,315 Sandstone, 1ight-gray, finegrained

1,315-1,350 Shale, gray, silty

TOP OF CASTLEGATE SANDSTONE

1,350-1,450 Sandstone, 1ight-gray

1,450-1,505. Sandstone and shale, dark-gray

TOP OF BLACKHAWK FORMATION

1,505-1,650 Shale, dark-gray; mudstone, darkgray

$1,650-1,750$ Shale, gray

Total depth: $1,750 \mathrm{ft}$

\begin{tabular}{l|l|l|l} 
Gam & Den & Cal & Res
\end{tabular}


Hole No.

BC-5-W

(continued)

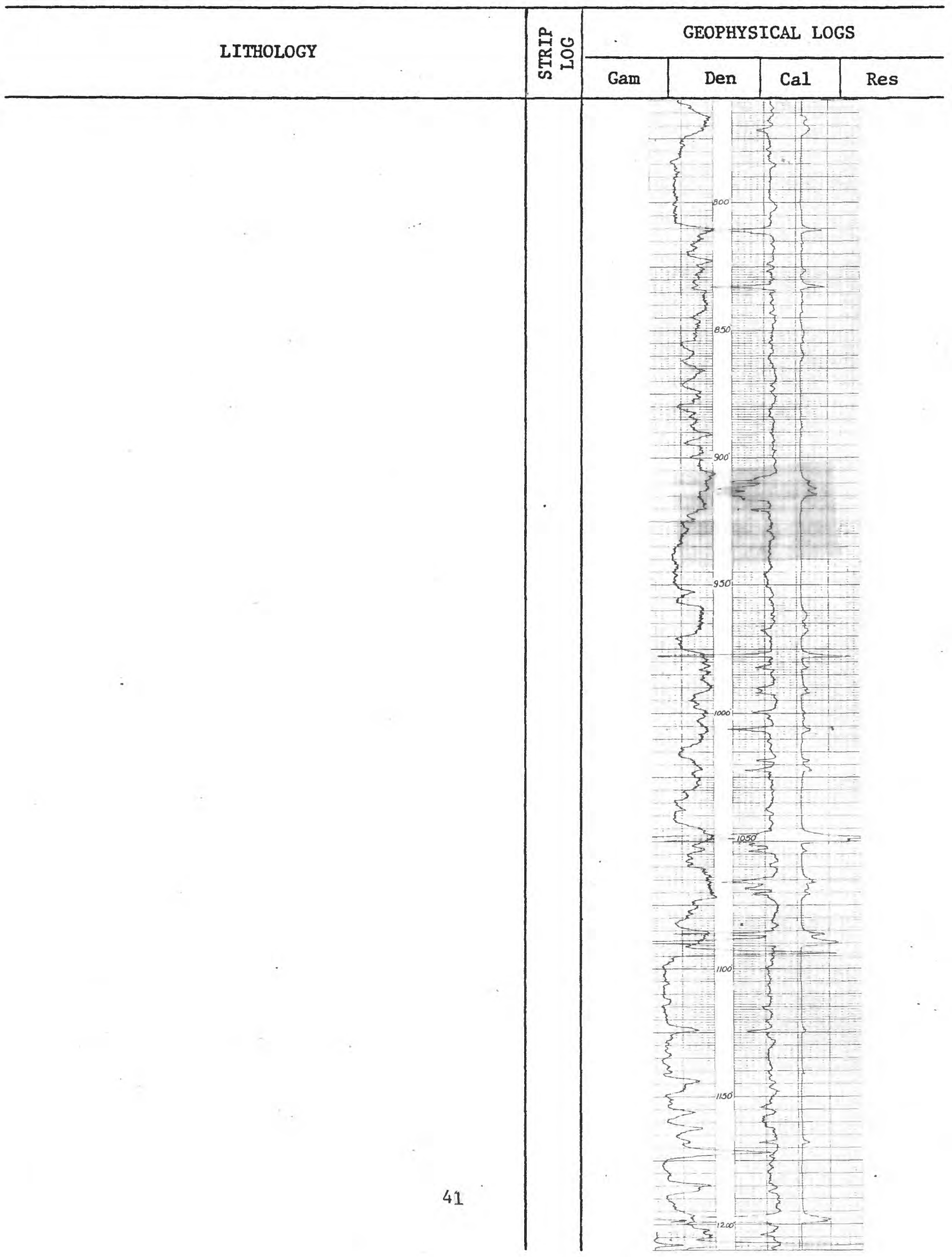


Hole No.

BC-5-W

(continued)

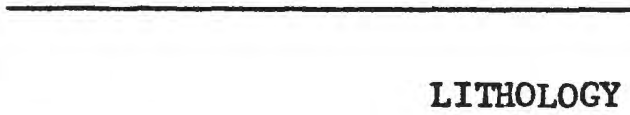

\begin{tabular}{|c|c|c|c|c|}
\hline \multirow{2}{*}{ 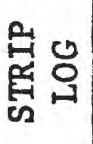 } & \multicolumn{4}{|c|}{ GEOPHYSICAL LOGS } \\
\hline & Gam & Den & Cal & Res \\
\hline
\end{tabular}


Hole No.

BC-5-W

(continued)

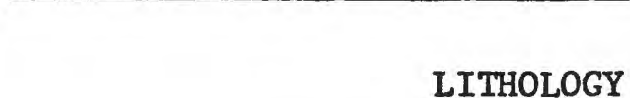

LITHOLOGY

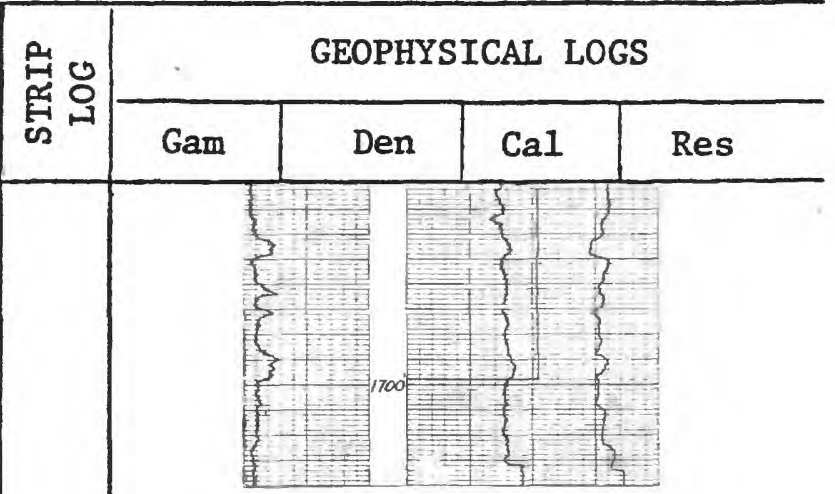


Hole iNo. BC-6-W Quadrangle Woodside Elevation 6,250 ft

Location: T. 17 S., R. 15 E., sec. $19,450^{\prime}$ FNL $700^{\prime}$ FEL

Rotarydrilled depth $759.4^{\prime}$

Cored interval 759.4-961.8 Logged depth .961' Total depth 961.8 Drilling medium Mud

Geophysica1 1ogs:

Caliper (Cal) - Logging speed: $40 \mathrm{ft} / \mathrm{min}$. Others: $20 \mathrm{ft} / \mathrm{min}$

Resistivity (Res):

Scale: $2 \Omega / \log$ div.

Gamma (Gam):

T.C. 1 sec.

Density (Den):

T.C. 1 sec.

Scale: $20 \mathrm{cps} / 1 \mathrm{log}$ div.

Scale: $2.00 \mathrm{cps} / \mathrm{log}$ div.

Remarks:

\section{LITHOLOGY}

0- 10 Alluvial sand, yellowish-brown

10- 20 Shale, brown

TOP OF PRICE RIVER FORMATION

20- 35 Mudstone, medium-gray

35- 70 Sandstone, ye1lowish-brown, finegrained; mostly quartz

70- 80 Shale, dark-gray, carbonaceous

80-105 Sandstone, yellowish-brown, as above

105-110 Mudstone, medium-gray

110-120 Sandstone, yellowish-brown, as above

120-130 Mudstone, medium-gray

130-140 Shale, silty, light-brown

140-150 Mudstone, dark-gray

150-155 Sandstone, yellowish-brown, finegrained

155-160 Shale, dark-gray, carbonaceous

160-175 Sandstone, yellowish-brown, finegrained

175-205 Mudstone, medium-gray

205-225 Sandstone, yellowish-brown, finegrained

225-250 Mudstone, medium-gray

250-255 Sandstone, yellowish-brown, finegrained

255-260 Shale, chocolate-brown

260-290 Mudstone, dark-gray

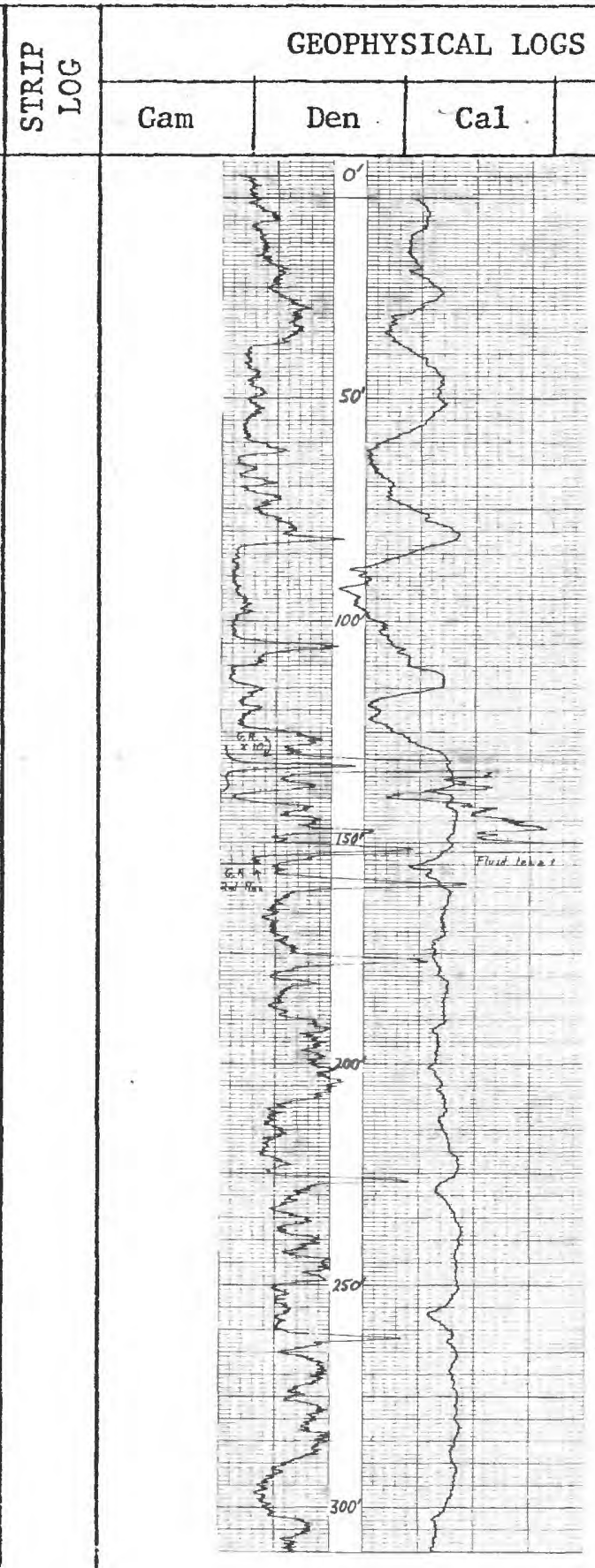




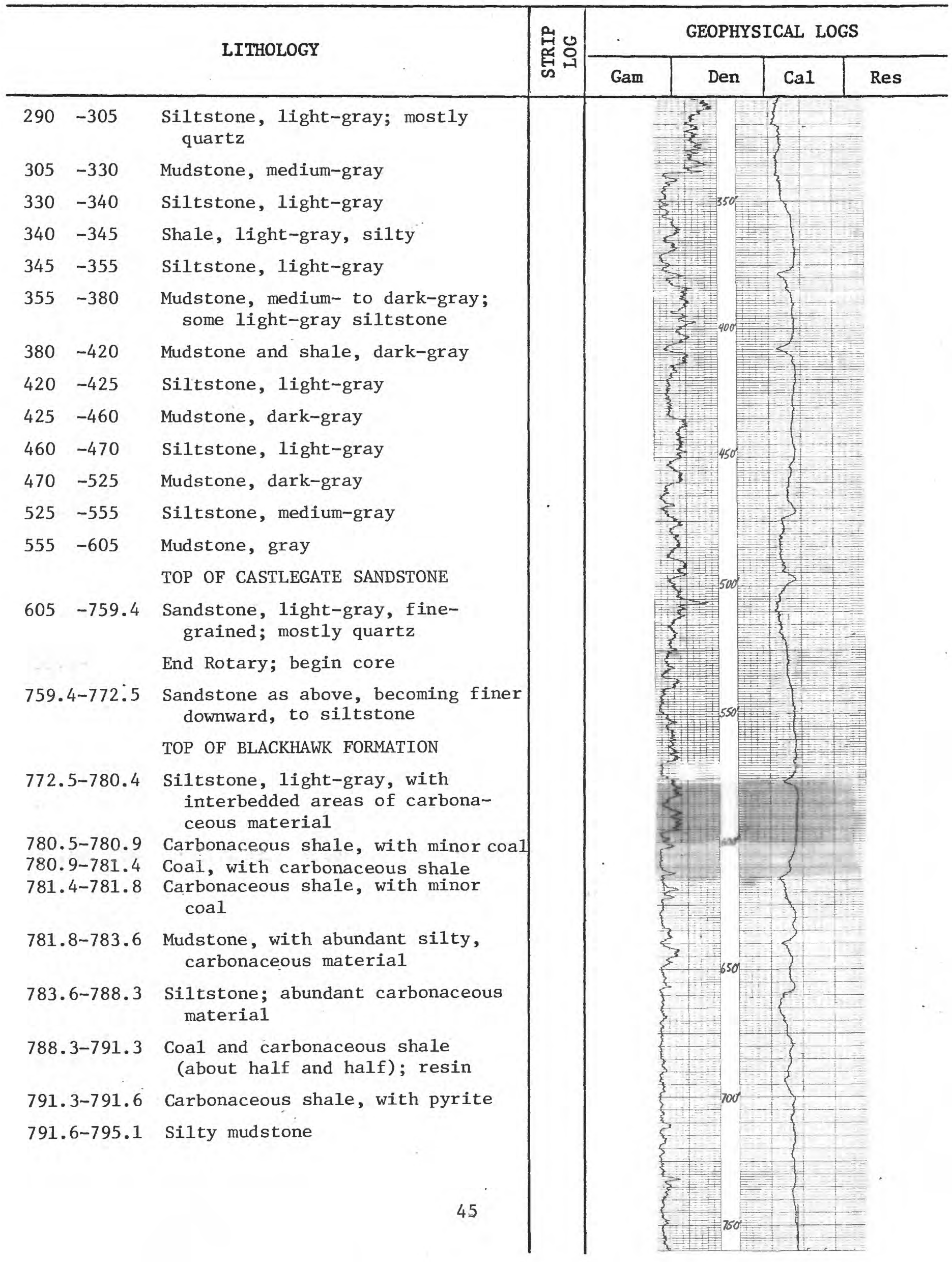




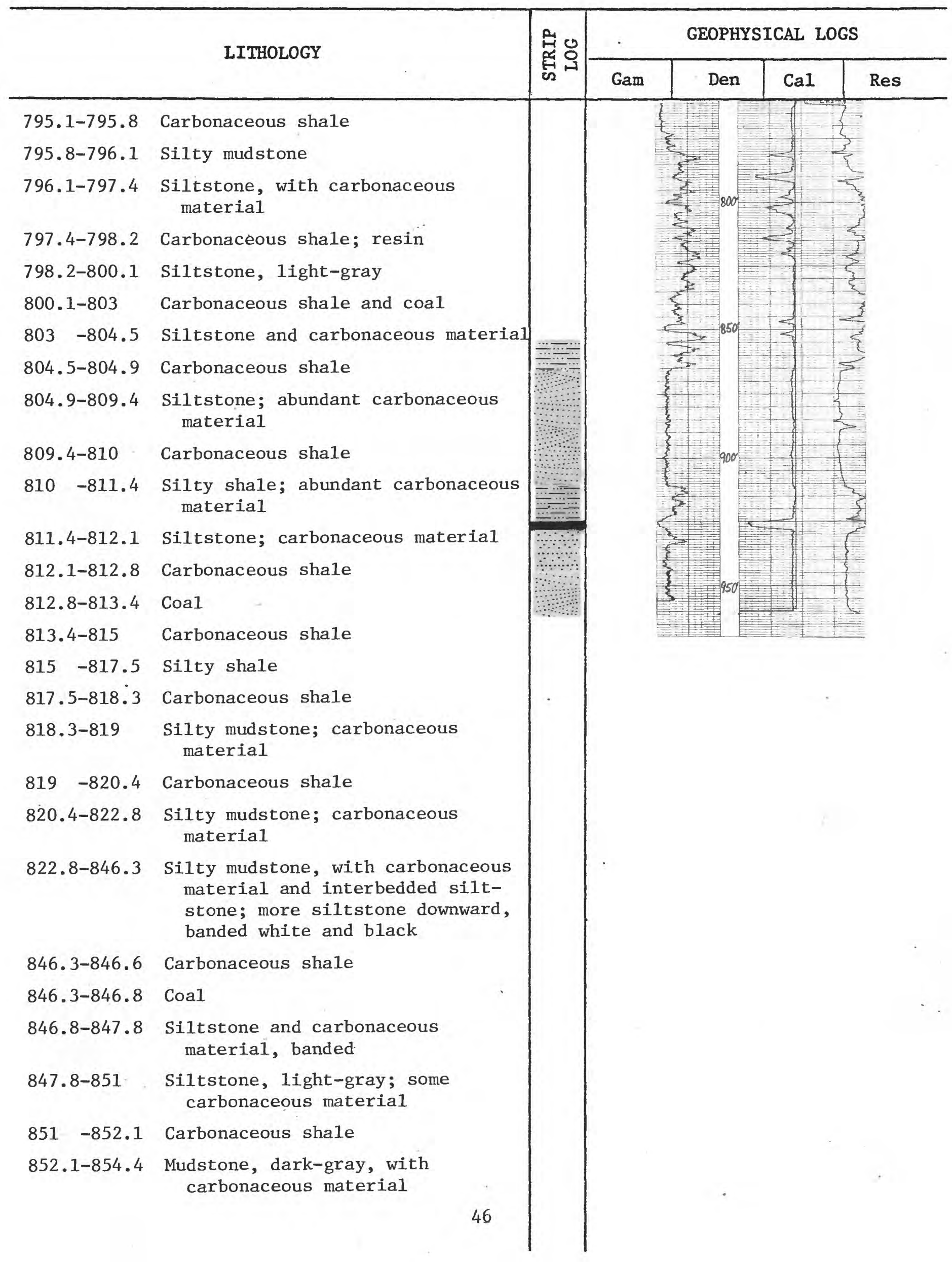


Hole No. BC-6-W

(continued)

\begin{tabular}{|c|c|c|c|c|c|}
\hline \multirow{2}{*}{ LITHOLOGY } & \multirow{2}{*}{ 䓢 } & \multicolumn{4}{|c|}{ GEOPHYSICAL LOGS } \\
\hline & & Gam & Den & $\mathrm{Cal}$ & Res \\
\hline
\end{tabular}

854.4-864.8 Siltstone and carbonaceous material, banded

864.8-911.4 Sandstone, fine-grained, friable; crossbedding; some dark layering

911.4-924.5 Siltstone and carbonaceous material, interbedded, banded

924.5-927.6 Coal. Sunnyside bed

927.6-928.2 Carbonaceous shale

928.2-961.8 Sandstone, grayish, fine-grained, massive at top; crossbedded at bottom; dark bands; some layering

Total depth: $961.8 \mathrm{ft}$ 
Hole No. BC-7-W Quadrangle Woodside Elevation $6,150 \mathrm{ft}$

Location: T. 17 S., R. 15 E., sec. $30,900^{\prime} \mathrm{FEL} \underline{1,450^{\prime}}$ FNL

Rotarydrilled depth $985^{\prime}$
Cored interval Drilling medium Logged depth $984^{\prime}$ Total depth $985^{\prime}$ Air and foam

Geophysical logs:

Caliper (Ca1) - Logging speed: $40 \mathrm{ft} / \mathrm{min}$. Resistivity (Res):

Gamma (Gam):

T.C. 1 sec.

Density (Den):

T.C. 1 sec.

Others: $\frac{20 \mathrm{ft} / \mathrm{min}}{10 \Omega / \log \mathrm{div} .}$
Scale: $\frac{20 \mathrm{cps} / \mathrm{log} \mathrm{div} .}{200 \mathrm{cps} / 1 \mathrm{~g} \mathrm{div} .}$
Scale:

Remarks:

Drilling

LITHOLOGY

0- 7 Sandstone, brown, medium-grained

7- 20 Shale, brown

20- 25 Limestone to limy sandstone, finegrained

25- 30 Sandstone, gray, medium- to finegrained

30- 40 . Sandstone, gray, fine-grained

40- 47 Limy sandstone, gray

47- 65 Sandstone, medium-grained, we11rounded, clean

65- 70 Sandstone, medium-grained; some carbonaceous shale, gray

70- 75 Sandstone, coarse-grained

75- 80 Sandstone, fine-grained; gray shale

80- 85 Siltstone, gray, to carbonaceous siltstone

TOP OF PRICE RIVER FORMATION

85-175 Sandstone, medium-grained, wel1sorted, very clean

175-190 Siltstone, gray

190-215 Sandstone, medium-grained, wel1sorted, clean

2I5-225 Siltstone, gray to dark-gray

225-245 Sandstone, gray, medium-grained

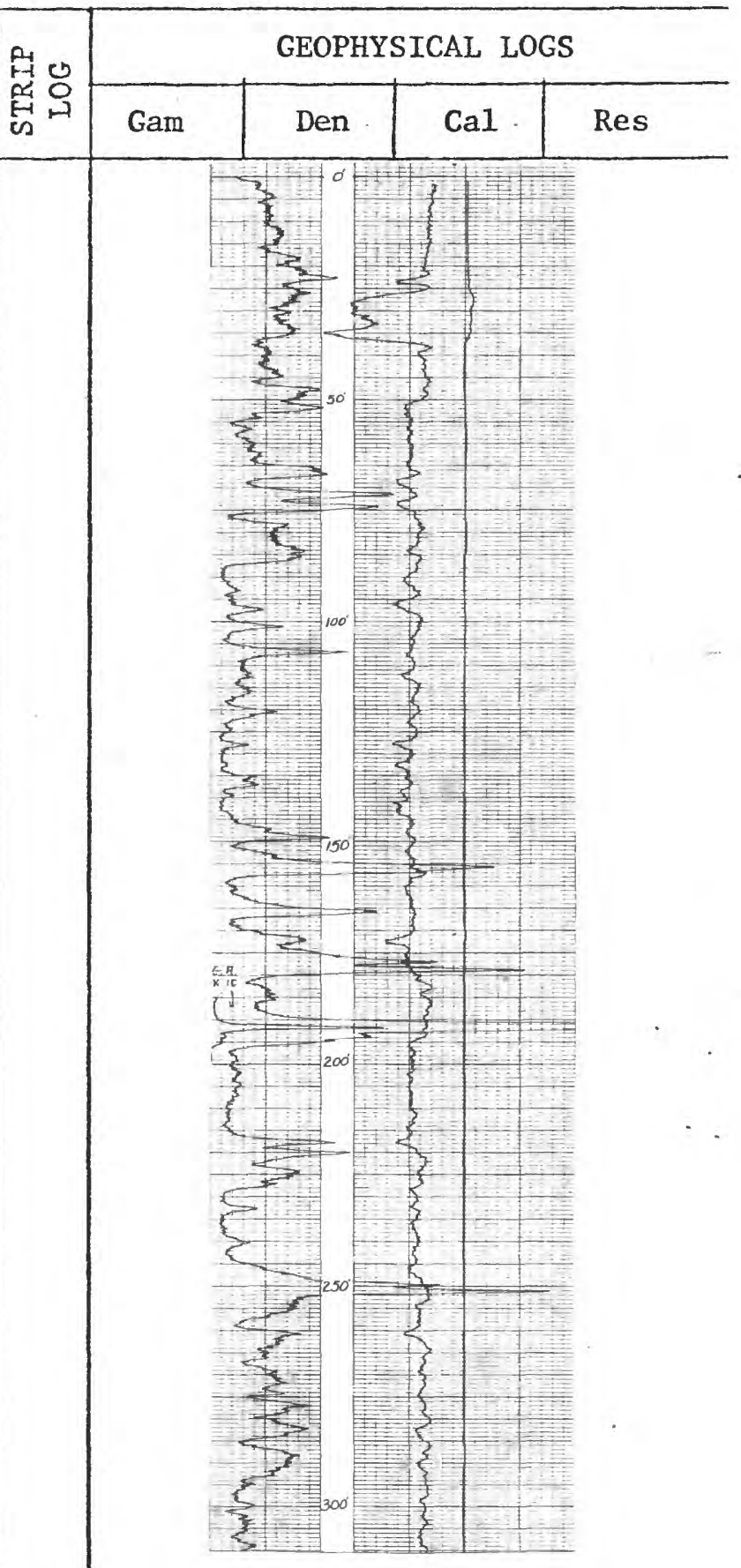




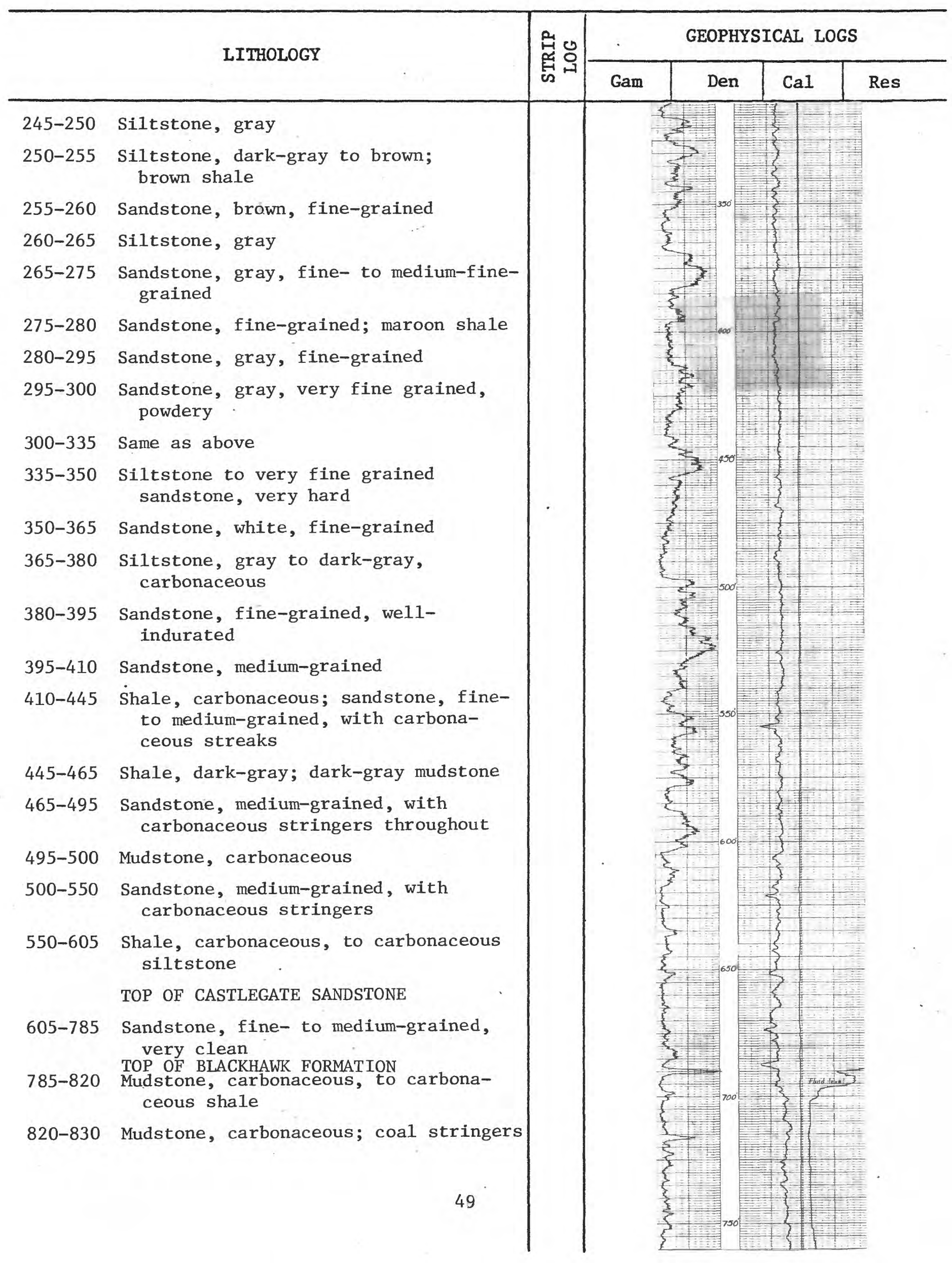


Hole No.

BC-7-W

(continued)

\begin{tabular}{ll}
\hline \multicolumn{2}{c}{ LITHOLOGY } \\
\hline $830-880$ & $\begin{array}{l}\text { Shale and sandstone; some carbona } \\
\text { ceous stringers }\end{array}$ \\
$880-940$ & Sandstone, medium-grained, clean \\
$940-945$ & Coal. Sunnyside bed \\
$945-984$ & Sandstone, medium-grained, clean \\
& Total depth: $985 \mathrm{ft}$
\end{tabular}


Hole No. BC-8-W Quadrangle Woodside Elevation $5,950 \mathrm{ft}$

Location: T. 17 S., R. 15 E., sec. 29 , 700' FSL 1,200! FWL

Rotarydrilled depth $771.3^{\prime}$

Cored interval 771.3-942' Logged depth 942 Total depth 942.1 Drilling medium Air and mud

Geophysical logs:

Caliper (Ca1) - Logging speed: $40 \mathrm{ft} / \mathrm{min}$. Resistivity (Res):

Gamma (Gam):

Density (Den):
T.C. 1 sec.

T.C. 1 sec.
Others: $20 \mathrm{ft} / \mathrm{min}$

Scale: $15 \Omega / 10 \mathrm{~g}$ div.

Scale: $20 \mathrm{cps} / \mathrm{log} \mathrm{div}$.

Scale: $200 \mathrm{cps} / \mathrm{log}$ div.

Remarks:

\section{LITHOLOGY}

0- 25 Sandstone, yellowish-brown

25- 35 Siltstone and mudstone, 1ight-gray, interbedded

TOP OF PRICE RIVER FORMATION

35-140 Sandstone, yellowish-brown, finegrained; minor siltstone and mudstone

140-150 Mudstone, medium-gray, silty

150-165 Sandstone, yellowish-brown, finegrained

165-170 Mudstone, dark-gray

170-180 Sandstone, ye11owish-brown

180-190 Mudstone, medium-gray

190-210 Sandstone, 1ight-gray, fine-grained

210-235 Mudstone, medium-gray

235-245 Siltstone, 1ight gray; mostly quartz

245-255 Mudstone, dark-gray

255-265 Siltstone, 1ight-gray

265-270 Mudstone, medium-gray

270-310 Siltstone and mudstone

310-320 Mudstone, medium-gray

320-360 Siltstone, 1ight-gray

360-395 Mudstone, medium-gray

395-405 Siltstone, 1ight-gray

\begin{tabular}{|c|c|c|c|c|}
\hline \multirow{2}{*}{ 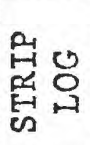 } & \multicolumn{4}{|c|}{ GEOPHYSICAL LOGS } \\
\hline & Gam & Den & $\mathrm{Cal}$ & Res \\
\hline
\end{tabular}




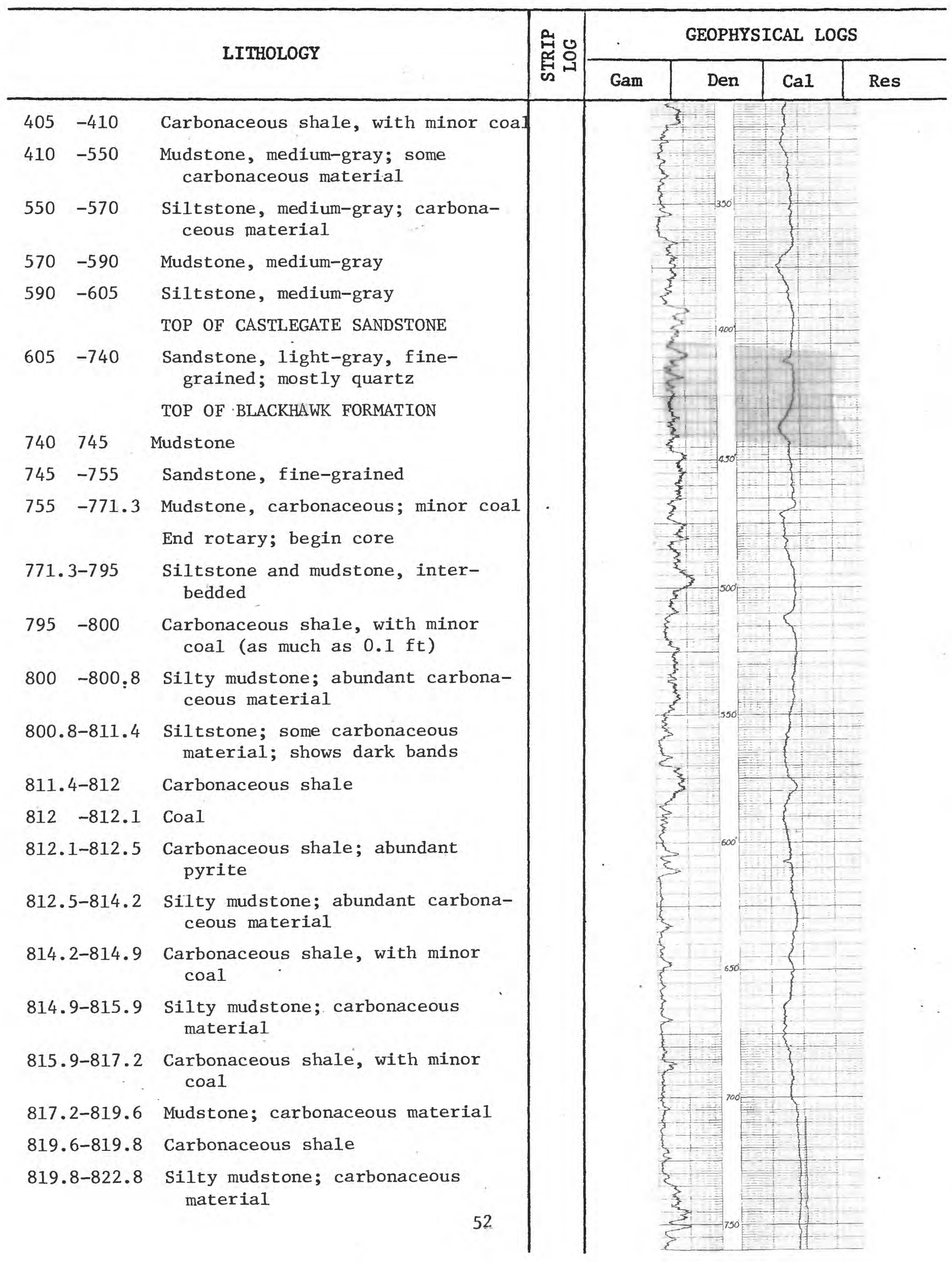




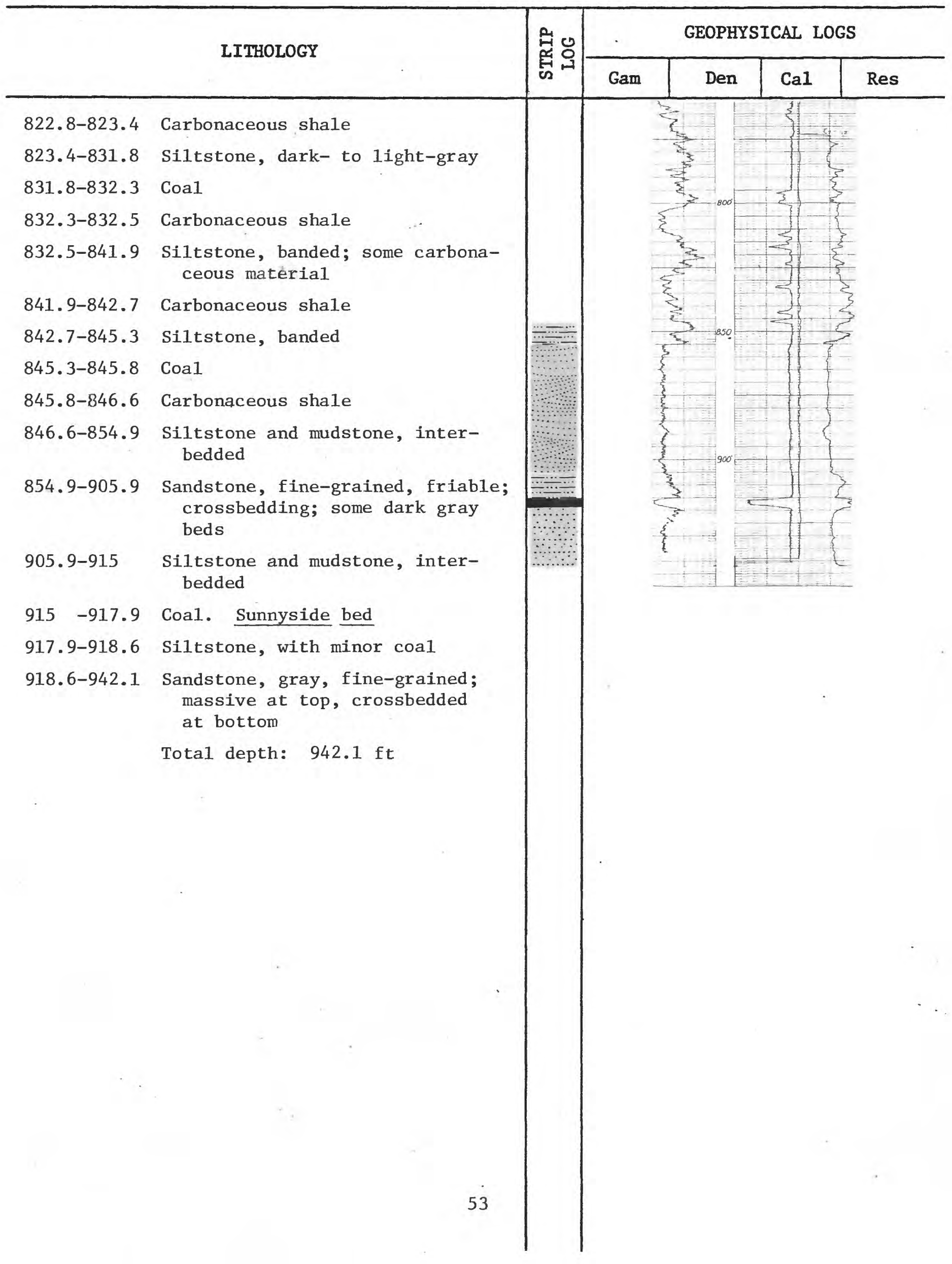


Hole No. BC-10-W

Quadrangle Woodside

Elevation $5,700 \mathrm{ft}$

Location: T. 17 S., R. 15 E., sec. 29, 700' FSL 1,150' FEL

RotaryCored interval Logged depth $984^{\prime}$ Total depth $990^{\prime}$ drilled depth $990 \mathrm{ft}$

Drilling medium Air and foam

\section{Geophysical logs:}

Caliper (Ca1) - Logging speed: $40 \mathrm{ft} / \mathrm{min}$.

Others: $20 \cdot \mathrm{ft} / \mathrm{min}$

Resistivity (Res):

Gamma (Gam):

T.C. 1 sec.

Density (Den):

T.C. $\frac{1}{1}$ sec.

Scale: $16.7 \Omega / \log$ div.

Scale: $20 \mathrm{cps} / \mathrm{log}$ div.

Scale: $200 \mathrm{cps} / 10 \mathrm{~g}$ div.

Remarks:

\section{LITHOLOGY}

Collared in North Horn Formation

0- 15 Siltstone, greenish-yellow

15- 40 Siltstone, medium-gray

40- 50 Shale, medium-gray

TOP OF PRICE RIVER FORMATION

50- 55 Sandstone, light-gray, fine-grained, friable

55- 65 Sandstone, yellow, medium-grained, well-rounded, friable

65-115 Sandstone, white, poorly sorted, friable; subangular grains of quartz

115-125 Sandstone, light-gray, fine-grained, quartzose, friable

125-130 Sandstone, white, fine-grained, quartzose, friable

130-135 Sandstone, 1ight-yellowish-brown, medium-grained, subrounded, friable

135-140 Shale, medium-gray

140-145 Sandstone, yellow, medium-grained, subrounded, friable

145-170 Shale, medium- to dark-gray; pyritic at $155 \mathrm{ft}$

170-180 Sandstone, light-gray, fine-grained

180-200 Shale, dark-gray; carbonaceous from 190 to $200 \mathrm{ft}$

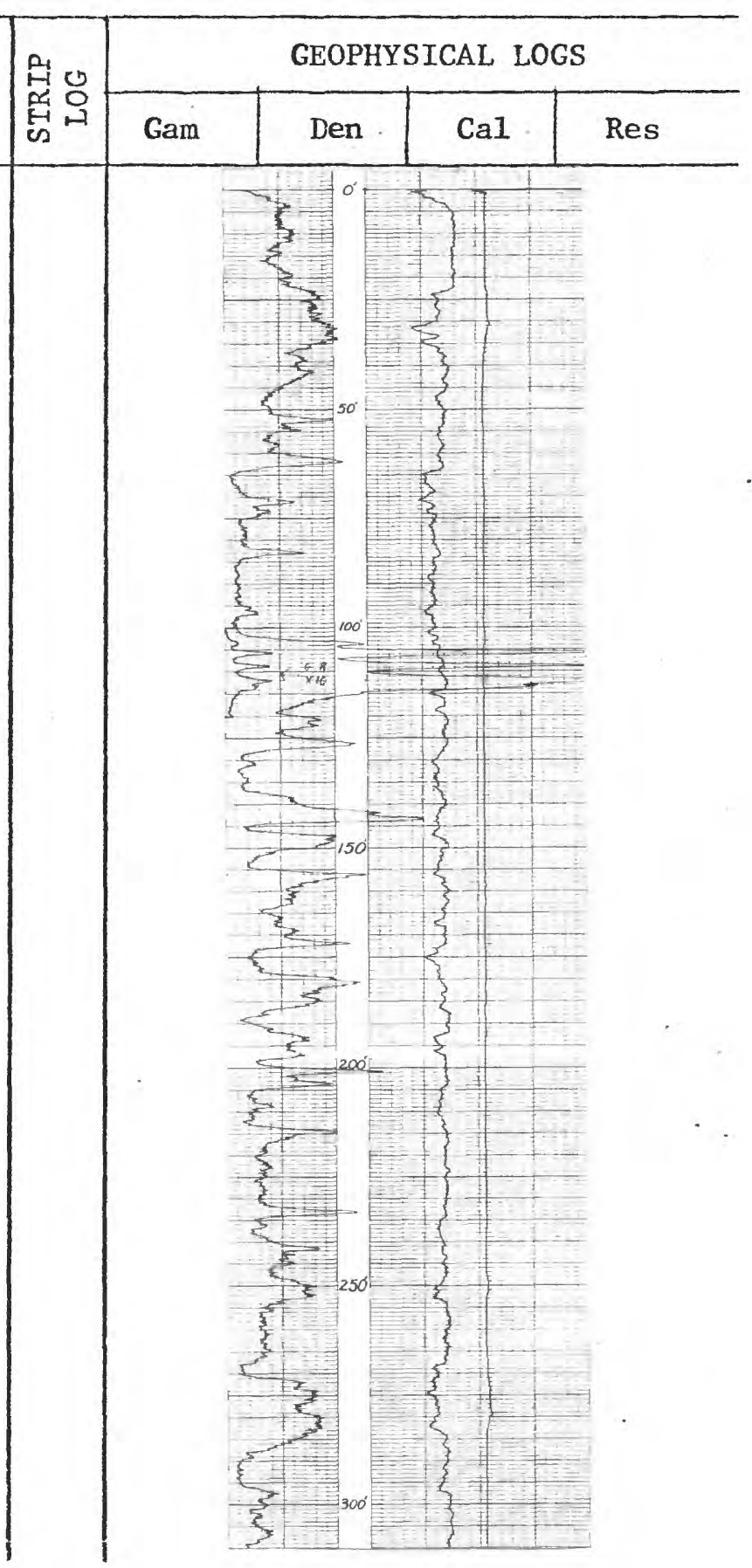




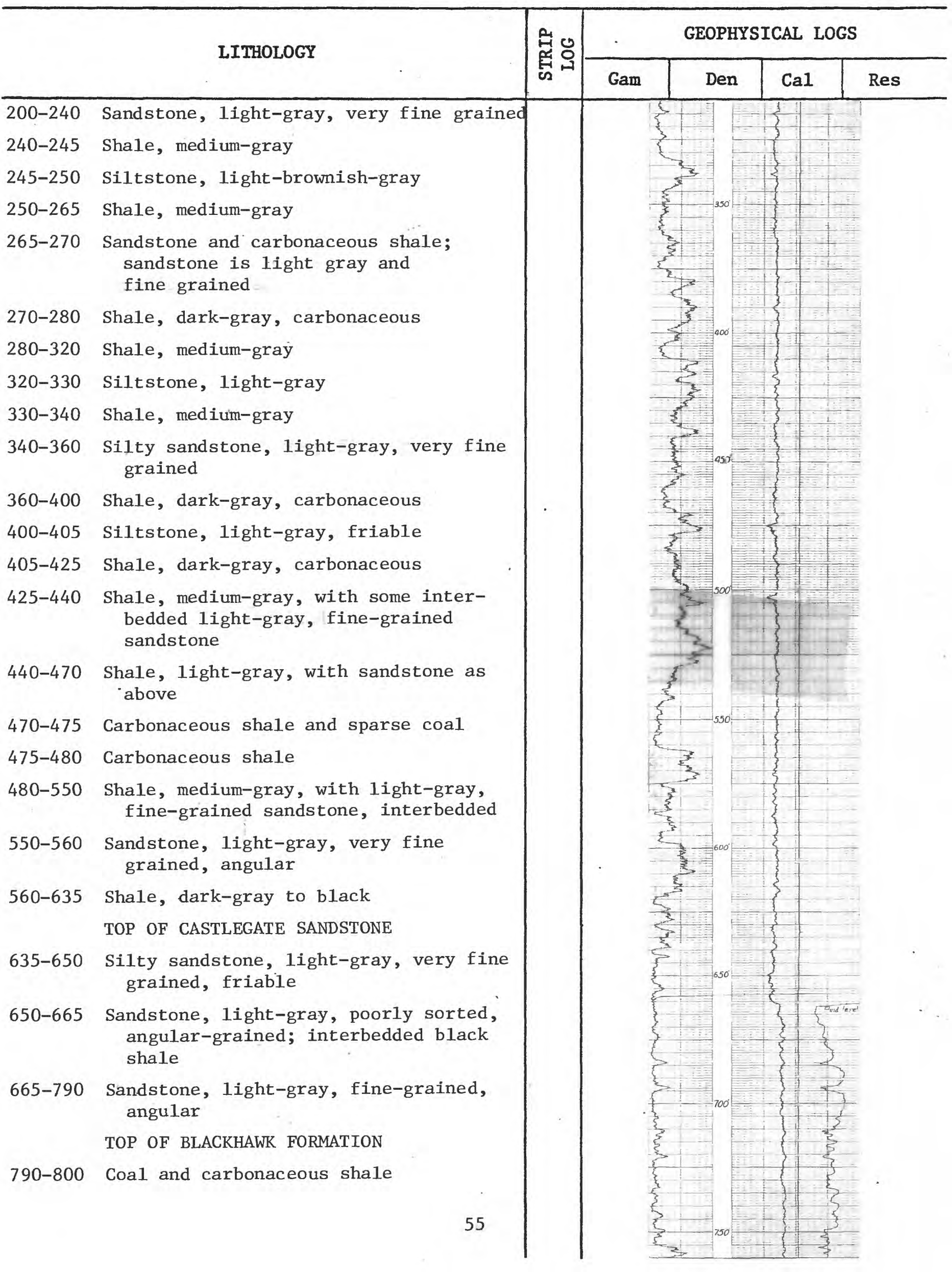




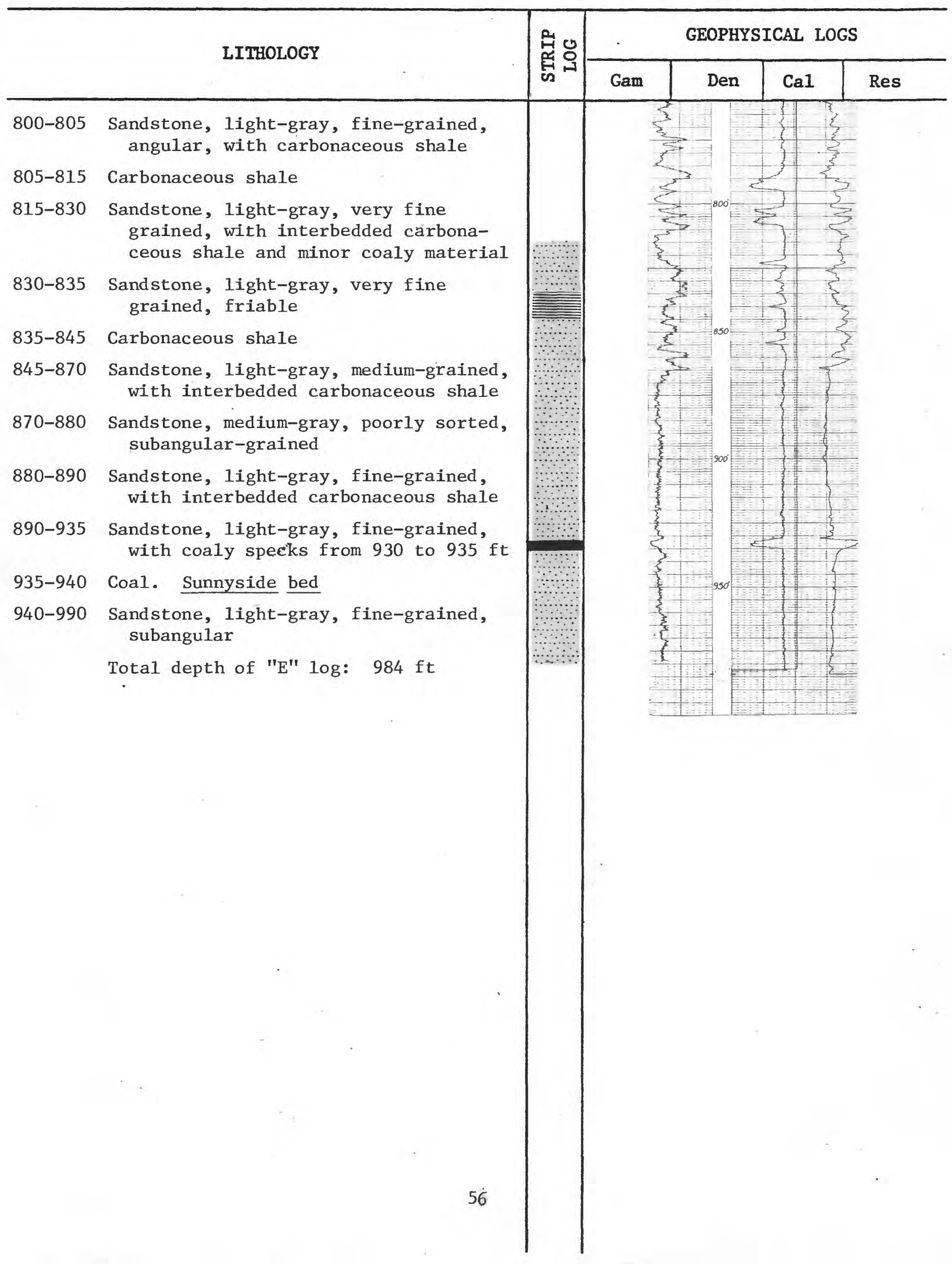

